\title{
Testing and Modeling Fuel Regression Rate in a Miniature Hybrid Burner
}

\author{
Luciano Fanton, Christian Paravan, and Luigi T. De Luca \\ SPLab, Aerospace Engineering Department, Politecnico di Milano, 34 Via La Masa, 20156 Milan, Italy \\ Correspondence should be addressed to Luciano Fanton, luciano.fanton@gmail.com
}

Received 10 February 2012; Accepted 7 May 2012

Academic Editor: Dario Pastrone

Copyright (C) 2012 Luciano Fanton et al. This is an open access article distributed under the Creative Commons Attribution License, which permits unrestricted use, distribution, and reproduction in any medium, provided the original work is properly cited.

\begin{abstract}
Ballistic characterization of an extended group of innovative HTPB-based solid fuel formulations for hybrid rocket propulsion was performed in a lab-scale burner. An optical time-resolved technique was used to assess the quasisteady regression history of single perforation, cylindrical samples. The effects of metalized additives and radiant heat transfer on the regression rate of such formulations were assessed. Under the investigated operating conditions and based on phenomenological models from the literature, analyses of the collected experimental data show an appreciable influence of the radiant heat flux from burnt gases and soot for both unloaded and loaded fuel formulations. Pure HTPB regression rate data are satisfactorily reproduced, while the impressive initial regression rates of metalized formulations require further assessment.
\end{abstract}

\section{Introduction}

HREs are propulsive systems combining chemical reactants in both a solid and a fluid (liquid or gaseous) state. In particular, the direct hybrid configuration studied in this work is characterized by a solid fuel reacting with a gaseous oxidizer. The main points of interest of this architecture include high specific impulse, relative construction simplicity, intrinsic handling safety, operational flexibility, minimal environment impact, and possible cost effectiveness compared to other systems, notably solid and liquid rocket engines $[1,2]$. On the other hand, a serious drawback of HREs is the low regression rate of the gasifying solid fuel surface that yields low thrust levels if simple grain geometries are implemented. The main reason of such behavior is the complex diffusive nature of the flame, as described by several investigators [3-6].

The development of novel energetic additives renewed the interest for hybrid rocket propulsion and brought a new generation of hybrid solid fuels, aiming at improving the relatively low regression rates of conventional HTPB-based formulations [7-9]. The main target for research activities on hybrid systems should be to improve the fuel regression rate and, subsequently, enhancing combustion efficiencies, while granting adequate mechanical properties, and commercial availability of the ingredients.

SPLab of Politecnico di Milano has developed a variety of experimental techniques and diagnostics in order to investigate ballistics of hybrid fuels and to achieve a relative grading of different fuel formulations in terms of regression rate. The present study is focused on a time-resolved technique for regression rate measurements. Collected data were considered to investigate the effects of radiant heat transfer on regression rate of loaded and nonloaded HTPBbased fuel formulations.

\section{Literature Survey}

In a direct HRE, the oxidizer flow over the solid fuel grain generates a boundary layer. After the ignition, the vaporized fuel diffuses into the oxidizer flow. Thus a flame is established in the boundary layer, where the mixture $O / F$ reaches the flammability limits of the reactants. Heat transfer from the flame to the solid fuel grain gasifies new fuel thus sustaining the process. Fundamentals of hybrid combustion were investigated by Marxman et al. [3, 4], who identified convective heat transfer as the driving phenomenon for solid 
fuel regression. The $r_{f}$ of solid grains was evaluated as a strong function of the total mass flux $G=G_{f}+G_{\text {ox }}$, and, more precisely, $r_{f} \propto G^{0.8}$. Similar results were achieved by Smoot and Price [10]. In most experimental studies, $r_{f}$ was evaluated by TOT techniques. In recent research activities conducted at Pennsylvania State University, instantaneous regression rate measurements were performed and $r_{f} \propto$ $G^{0.61}$ was found for tests on HTPB burning in GOX [7].

The presence of soot and solid fuel fragments leads to a contribution of radiant heat transfer on $r_{f}[1,7]$. The purely convective model was extended by Marxman et al. in order to take into account the radiant heat transfer [3]: the total heat flux to the solid grain was considered as the sum of convective and radiant heat fluxes. Radiation effects on regression rate were investigated also by Strand et al. [11], Estey et al. [12], and the research team of Pennsylvania State University [13]. The work by Strand et al., in particular, suggested that radiant heat flux due to combustion gaseous products such as $\mathrm{CO}, \mathrm{CO}_{2}, \mathrm{H}_{2} \mathrm{O}$, and soot particles could significantly influence hybrid combustion process. According to their results, radiant heat transfer accounts for nearly $50 \%$ of the total heat flux and is reduced by increasing $O / F$. The Pennsylvania State University research team observed a regression rate dependence on $p_{c}$, under the investigated conditions, leading to semiempirical correlations for combustion data interpolation. The contribution of radiant heat flux was found to mainly depend on the presence of soot, the radiation of combusted gases being quite low; hence, under the investigated conditions, convection has a high relative weight in the initial part of the combustion process, while radiation is more effective at lower values of the oxidizer mass flux.

One of the most promising ways to obtain $r_{f}$ enhancement in hybrid systems is to increase the heat feedback from the flame to the solid fuel, by including highly energetic additives in the fuel matrix. Various ingredients have been tested in the recent past. Significant $r_{f}$ enhancements were observed by adding $\mathrm{nAl}$ or boron-based composite metals [9]. This can be explained by the fact that these metalized ingredients combine high energy release and high reactivity, as shown by their large specific energy $(\sim 30 \mathrm{~kJ} / \mathrm{g}$ for $\mathrm{Al}$ and $\sim 59 \mathrm{~kJ} / \mathrm{g}$ for $\mathrm{B}$, the highest among nonhazardous metals or metalloids) with large specific surface values $\left(\sim 10 \mathrm{~m}^{2} / \mathrm{g}\right.$ for $\mathrm{nAl}$ versus $\sim 1 \mathrm{~m}^{2} / \mathrm{g}$ for conventional micron-sized additives). These characteristics favor short ignition delays and intense heat release near the regressing surface. Adding high-energy metal powders to the polymeric binder also increases the fuel density and therefore the engine volumetric specific impulse $[9,14,15]$.

Among the undesirable characteristics of metal additives, one can recognize the tendency of both aluminum and boron to create an oxide layer during storage and fuel manufacturing. This implies a marked decrease of the particle reactivity (at least until the oxide is removed during the combustion phase) and a lower active metal content in the powders. An additional shortcoming of nanosized additives is their tendency to create clusters [9]. This requires proper manufacturing procedures in order to disperse the nano-sized additives down to the nanoscale. Micron-sized additives do not require any dedicated dispersion technique.

\section{Experimental Setup and Data Handling}

3.1. Experimental Rig. The SPLab 2D radial burner utilized in this work enables a relative ballistic grading of different fuel formulations under controlled operating conditions (see Figure 1). The tested strands have a cylindrical shape and a single central port perforation. Each solid fuel grain is accommodated in a stainless steel case with $30 \mathrm{~mm}$ length. The strand outer diameter is $18 \mathrm{~mm}$, while its nominal initial port diameter is $4 \mathrm{~mm}$, thus yielding a solid fuel web thickness of $7 \mathrm{~mm}$. Different cases enable testing of samples with different outer diameters (thus reducing the solid grain web thickness for a given $D_{0}$ ). Use of different mandrels enables the testing of strands with different $D_{0}$.

The implemented experimental rig provides a continuous visualization of the head-end of the tested strand, thus it is possible to track the central port diameter during combustion. Video recording of the combustion processes enables $r_{f}$ measurement by an optical, nonintrusive technique. Independent regulations of $\dot{m}_{\mathrm{ox}}$ and $p_{c}$ are possible by a variable area flowmeter and by a pressure regulator driving a set of electric valves. The maximum values of the operating parameters are $6 \mathrm{~g} / \mathrm{s}$ for $\dot{m}_{\mathrm{ox}}$ and 20 bar for pressure. Sample burning is initiated by a pyrotechnic primer charge. The latter is in turn ignited by a $\mathrm{CO}_{2}$ laser. Video acquisition was operated with a dedicated analog camera (burning visualization at $25 \mathrm{fps}$, video resolution $640 \times 480$ pixels).

3.2. Time-Resolved Regression Rate. The main observable of interest for solid fuel ballistics is $r_{f}$. Thanks to the original design of the $2 \mathrm{D}$ radial burner, the latter parameter can be measured sampling the central port diameter of the visible head-end section of the cylindrical strand [16]. The diameter measurement starts when the central port perforation becomes visible following the primer charge ignition. For each sampling time, the space-average central port diameter is defined starting from local diameters measured along different radial directions, as shown in Figure 2. For a given sampling time, the so measured single diameters are averaged as in (1). Average diameters are obtained from the recorded combustion visualization with a sampling frequency of some $\mathrm{Hz}$ depending on the $r_{f}$. The resulting set of sampled $\bar{D}_{i}(t)$ is a discrete information in time. The latter becomes a continuous information in time by a proper data interpolation of the discrete $\bar{D}_{i}(t)$ thanks to (2), $[17,18]$ :

$$
\begin{gathered}
\bar{D}_{i}\left(t_{i}\right)=\frac{D_{1, i}+D_{2, i}+D_{3, i}+D_{4, i}}{4}, \\
\bar{D}(t)-D_{0}=a_{D} \cdot\left(t-t_{0}\right)^{n_{D}}, \quad t \geq t_{\text {ign }}>t_{0} .
\end{gathered}
$$

The latter (2) is valid starting from $t_{\mathrm{ign}}$. This parameter is defined adhoc as the one maximizing the data fitting of 


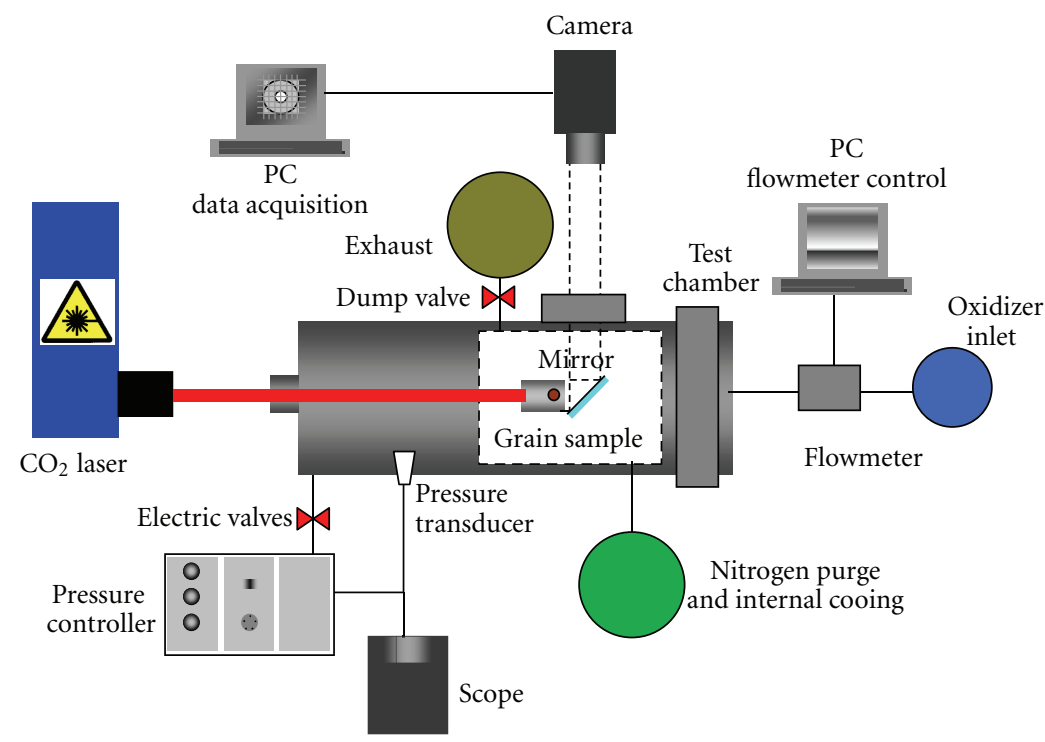

FIGURE 1: Experimental setup scheme highlighting the axial oxidizer inlet, the laser ignition apparatus, and the data acquisition hardware [16]. Note the $45^{\circ}$ mirror enabling sample head-end visualization.

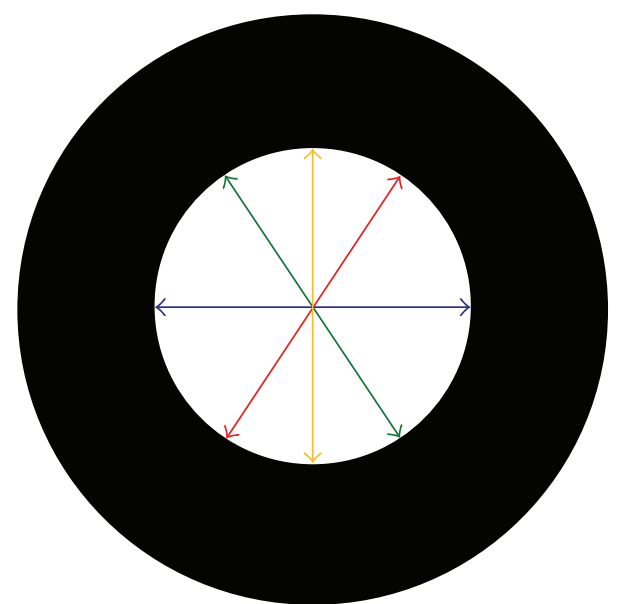

Figure 2: Single diameters measured along different radial directions.

(2) when associated with the discrete sampling of spaceaverage port diameters. A straightforward time derivative of (2) allows defining $r_{f}(t)$ as

$$
\begin{aligned}
r_{f}\left(t \geq t_{\text {ign }}\right) & =\frac{d}{d t}\left(\frac{\bar{D}(t)-D_{0}}{2}\right) \\
& =\frac{1}{2} a_{D} n_{D}\left(t-t_{0}\right)^{n_{D}-1}, \quad r_{f}\left(t<t_{\text {ign }}\right)=0 .
\end{aligned}
$$

The above expressions make it possible to determine all of the ballistic parameters of interest. The definitions of the time-resolved $G_{\mathrm{ox}}(t), \dot{m}_{f}(t)$, and $O / F(\mathrm{t})$ are respectively obtained as

$$
\begin{gathered}
G_{\mathrm{ox}}\left(t \geq t_{\mathrm{ign}}\right)=\frac{\dot{m}_{\mathrm{ox}}(t)}{\pi \bar{D}^{2}(t) / 4}=\frac{\dot{m}_{\mathrm{ox}}(t)}{\pi\left[D_{0}+a_{D}\left(t-t_{0}\right)^{n_{D}}\right]^{2} / 4}, \\
\dot{m}_{f}\left(t \geq t_{\mathrm{ign}}\right)=\rho_{f} A_{f}(t) r_{f}(t)=\rho_{f} \pi \bar{D} L_{s} r_{f}(t), \\
\frac{O}{F\left(t \geq t_{\mathrm{ign}}\right)}=\frac{\dot{m}_{\mathrm{ox}}(t)}{\dot{m}_{f}(t)}=\frac{\dot{m}_{\mathrm{ox}}(t)}{\rho_{f} \pi \bar{D}(t) L_{s} r_{f}(t)} .
\end{gathered}
$$

In order to check the consistency of the time-resolved data reduction technique, all collected results are verified by the conventional TOT technique often used in the literature. The main advantage of the TOT technique is its formal independency from the ignition transient, as shown by (7) and (8). On the other hand, TOT results are intrinsically affected by relatively large errors especially when evaluated over small time intervals [17], being

$$
\begin{gathered}
r_{f, i+1 / 2}=\frac{1}{2} \frac{\bar{D}_{i+1}-\bar{D}_{i}}{t_{i+1}-t_{i}}, \\
G_{\mathrm{OX}, i+1 / 2}=\frac{\dot{m}_{\mathrm{OX}}}{\pi \cdot\left(\bar{D}_{i+1}+\bar{D}_{i}\right)^{2} / 16} .
\end{gathered}
$$

In particular, a consistency test on the time-average regression rate is easily achieved by comparing the overall TOT regression rate (9) with the time-average analytical regression rate (10). The corresponding expressions for 
the consistency check on $G_{\text {ox }}$ are reported in (11) and (12) as follows:

$$
\begin{gathered}
\left\langle r_{f}\right\rangle_{\text {TOT }}=\frac{1}{2} \frac{\bar{D}_{\text {end }}-\bar{D}_{\text {ign }}}{t_{\text {end }}-t_{\text {ign }}}, \\
\left\langle r_{f}\right\rangle_{\text {an }}=\frac{1}{t_{\text {end }}-t_{\text {ign }}} \int_{t_{\text {ign }}}^{t_{\text {end }}} r_{f_{i}}(t) d t, \\
\left\langle G_{\text {OX }}\right\rangle_{\text {TOT }}=\frac{\dot{m}_{\text {ox }}(t)}{\pi \cdot\left[\left(\bar{D}_{\text {end }}+\bar{D}_{\text {ign }}\right)^{2}\right] / 16}, \\
\left\langle G_{\text {ox }}\right\rangle_{\text {an }} \frac{1}{t_{\text {end }}-t_{\text {ign }}} \int_{t_{\text {ign }}}^{t_{\text {end }}} G_{\text {ox }}(t) d t .
\end{gathered}
$$

A consistency test on the measured initial regression rate is achieved comparing the time-resolved experimental initial regression rate (reported in (13)) with the corresponding value calculated as shown in the following (14):

$$
\begin{aligned}
r_{f}\left(t_{\mathrm{ign}}\right) & =\frac{1}{2} a_{D} n_{D}\left(t_{\mathrm{ign}}-t_{0}\right)^{n_{D}-1}, \\
r_{f_{i}} & =\frac{1}{2} n_{D} \frac{\bar{D}_{\mathrm{ign}}-D_{0}}{t_{\mathrm{ign}}-t_{0}} .
\end{aligned}
$$

The consistency of the adhoc defined ignition delay $\left(t_{\text {ign }}-\right.$ $t_{0}$ ) is checked comparing its value with the corresponding time based on a purely convective regime as suggested by Ohlemiller and Summerfield [19]:

$$
t_{\text {ign, convective }}=\frac{\pi}{4} \alpha\left[\frac{\rho_{f} \cdot C_{s} \cdot \Delta T_{s}}{h^{*} \cdot \Delta T_{g}}\right]^{2} .
$$

In this expression, the term $\Delta T_{s}$ represents the difference between final and initial solid fuel surface temperatures, while $\Delta T_{g}$ represents the difference between the flame temperature and the solid fuel temperature throughout the ignition transient (defined as the average value between ambient temperature and $T_{s}=820 \mathrm{~K}$ ). The flame temperature was determined by thermochemical equilibrium calculations carried out with the NASA CEA code. The required convective heat exchange coefficient $h^{*}$ was determined by the Gnielinski empirical correlation [20]:

$$
\mathrm{Nu}_{D}=\frac{(f / 8)\left(\operatorname{Re}_{D}-1000\right) \operatorname{Pr}}{1+12.7(f / 8)^{1 / 2}\left(\operatorname{Pr}^{2 / 3}-1\right)} .
$$

In the frame of the implemented time-resolved technique, each burning test yields an instantaneous $r_{f}$ curve, and this is subjected to several consistency checks (9)-(14) before acceptance. The different $\bar{D}(\mathrm{t})$ of the single tests performed for a given formulation, under the same set of operating conditions (strand geometry, $\dot{m}_{\mathrm{ox}}$ and $p_{c}$ ), are then used to extract the corresponding ensemble average by a single power law interpolation of the kind of (2). The data reduction technique is finalized by constructing the cumulative time-average trends for both instantaneous and ensemble average curves. In order to evaluate the error bars for a given ensemble, a proper time (or $G_{\mathrm{ox}}$ ) range is identified considering the limits where the curves of all the performed single tests are defined. Over this latter interval, the error bars are evaluated by confidence intervals centered on the average value resulting from single test diameters at a given time (for (2)) or regression rates at a given $G_{\text {ox }}$. Confidence intervals are evaluated with $95 \%$ accuracy.

3.3. Tested Formulations and Ingredients. After testing the pure HTPB baseline, an extensive set of metallized HTPBbased formulations, including a variety of high-energy ingredients (e.g., aluminum, magnesium, boron, and magnesium hydride), was examined with the intent of evaluating the resulting increase in regression rate. Composition and properties of the HTPB baseline solid fuel are reported in Table 1. This inert polymeric binder is extensively used in full-scale engines and lab-scale testing because of its good mechanical properties, resistance to ageing, ease of production, and relative cost effectiveness.

Most loaded formulations concern $\mathrm{nAl}$ particles: both ALEX and L-ALEX powders were tested. While having identical nominal diameter $(100 \mathrm{~nm})$, the two powders differ because ALEX is uncoated (passivation in air), while LALEX is coated with a palmitic acid layer [21-23]. The ALEX powder was also combined with carbon or titanium oxide, in order to assess possible effects on powder dispersion. Likewise, a formulation containing ALEX, carbon, and magnesium (mass mean diameter of $44 \mu \mathrm{m}$ ) was tested, in order to exploit the magnesium flammability to ignite the aluminum particles.

Boron-based composite metals were also tested (Section 2). Since boron ignition is rather difficult to achieve because of the high temperatures needed for a sustained combustion process, a compound of magnesium and boron $(\mathrm{MgB})$ was used. Mass composition of tested $\mathrm{MgB}$ composite is $20 \% \mathrm{Mg}$ and $80 \% \mathrm{~B}$, the latter component has a purity of 90\%; therefore, the composite can be referenced as MgB90 $(20 \% \mathrm{Mg})$. Particle size of $\mathrm{MgB}$ composite results submicrometric (mass mean diameter of $5.2 \mu \mathrm{m}$ ). Magnesium hydride (mass mean diameter of $47 \mu \mathrm{m}$ ) was also tested. Unfortunately this ingredient turns out to be particularly reactive with the HTPB polymeric binder, quickly oxidizing and reacting with the $\mathrm{OH}$ chemical groups. This way, macromolecules of polymeric binder are free to form a disorderedly reticulated compound with greatly increased viscosity. These unwanted effects limit the addition of magnesium hydrides powder to low mass percentages [24].

\section{Ballistic Characterization: Results and Discussion}

All results reported in this section were obtained under GOX at the same operating conditions: $p_{c}=10 \mathrm{bar}$ and $m_{\mathrm{ox}}=$ $1.67 \mathrm{~g} / \mathrm{s}$ (corresponding to an initial $G_{\mathrm{ox}}=140 \mathrm{~kg} /\left(\mathrm{m}^{2} \mathrm{~s}\right)$ ). For a matter of space, other results are not reported since they do not affect the general trends emerging at 10 bar.

4.1. HTPB Baseline. The ignition delay data are presented first and are reported in Figure 3. The numerically optimized 
TABLE 1: Baseline (HTPB) solid fuel formulation and ingredients density.

\begin{tabular}{lccc}
\hline Component (shorthand notation) & Mass fraction, \% wrt fuel mass & Density $\left(\mathrm{kg} / \mathrm{m}^{3}\right)$ & Supplier \\
\hline HTPB-R45 & 79.0 & 901 & Avio \\
DOA & 13.1 & 920 & Carlo Erba \\
IPDI & 7.67 & 1061 & Carlo Erba \\
TIN & 0.23 & 1321 & Carlo Erba \\
\hline HTPB binder & 100 & 915 & - \\
\hline
\end{tabular}

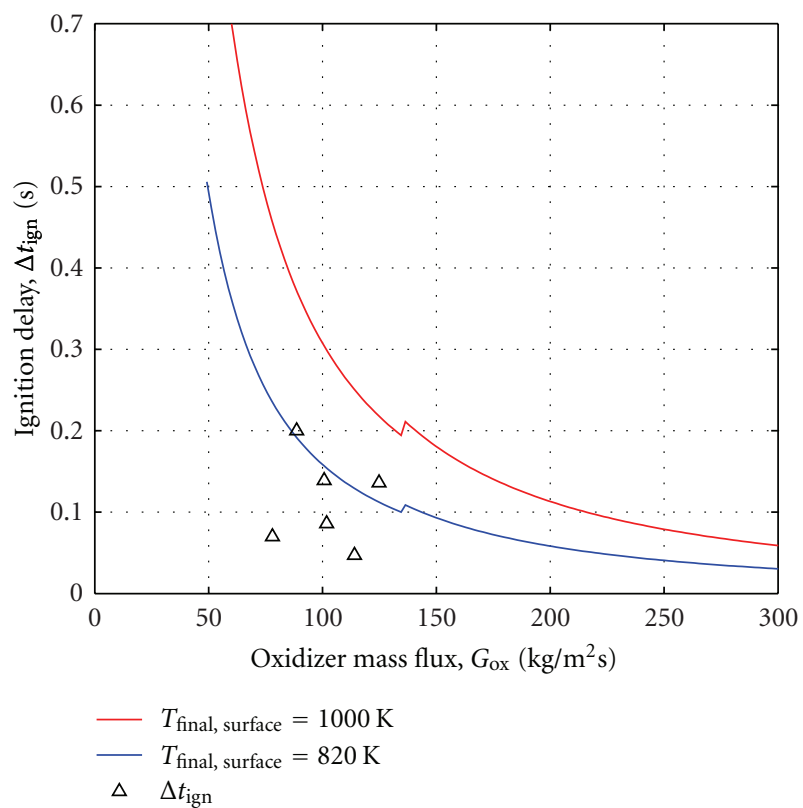

Figure 3: HTPB baseline: ignition delay. Experimental data and purely convective model by Ohlemiller and Summerfield [19], for two different final surface temperatures $[25,26]$.

ignition delays (see (2)) exhibit a general agreement with $\left(t_{\text {ign, convective }}-t_{0}\right)$ defined by $(15)$.

After this step, the data-reduction procedure presented in Section 3.2 was carried out and produced the results presented in Figures 4 and 5. The instantaneous diameter change in time (2) is first determined, then the instantaneous regression rate is evaluated. This plot underlines the strong dependence of the hybrid combustion on the process fluiddynamic properties, showing the highest regression rate in the initial combustion instants, when the oxidizer mass flux reaches its highest value. Notice that the oxidizer mass flux is maximum at ignition and then decreases in time, implying that, for all figures with oxidizer mass flux in the $x$-axis, time increases from right to left.

Figure 5 points out, with some data scattering, a similar ballistic response for all the HTPB tests: most of the curves show a steep initial slope and then a monotonic decrease in the final part of the combustion process.

In Figure 6, the instantaneous ensemble data are compared to the corresponding power law approximation, showing that a constant power does not provide a satisfactory estimate of the regression rate response in the initial part of

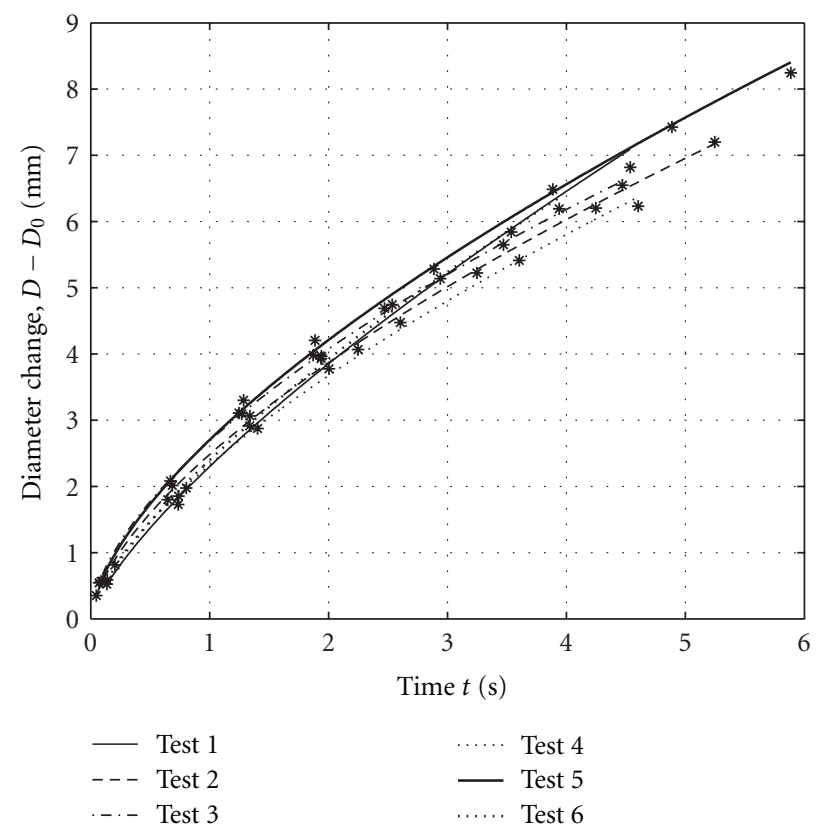

FIGURE 4: HTPB baseline: diameter change in time for all performed tests.

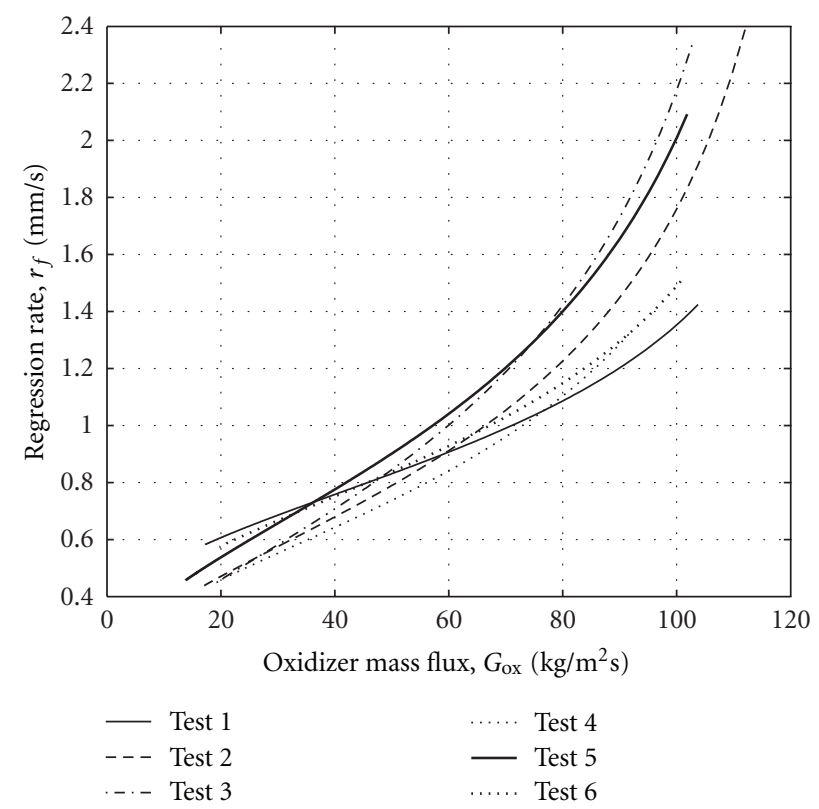

FIGURE 5: HTPB baseline: regression rate versus oxidizer mass flux for all performed tests. 


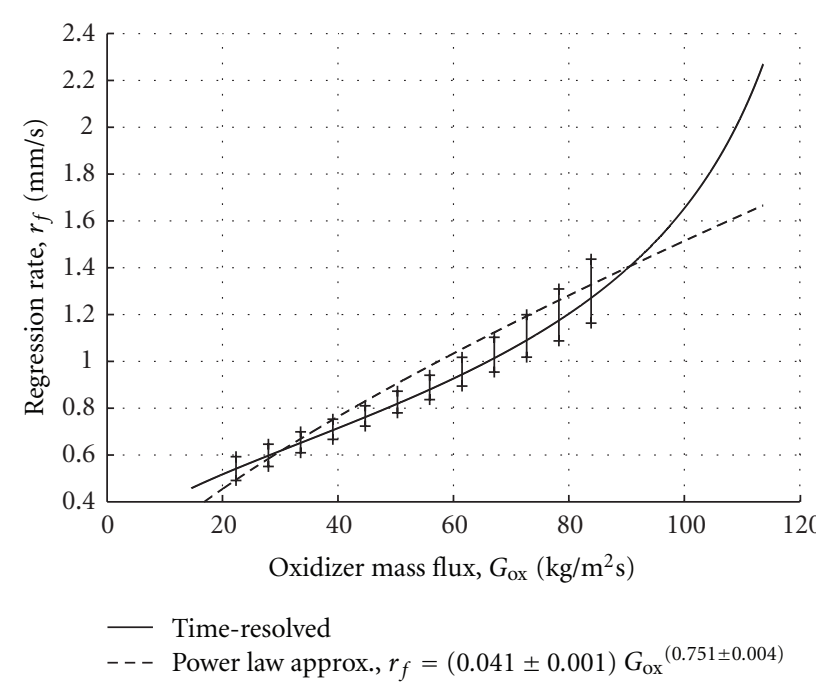

FIgURE 6: HTPB baseline: ensemble average, experimental data $r_{f}\left(G_{\text {ox }}\right)$ and power law approximation, highlighting the diverging trends for $G_{\mathrm{ox}}>100 \mathrm{~kg} / \mathrm{m}^{2}$ s.

the combustion process (say, $90 \leq G_{0 x} \leq 110 \mathrm{~kg} /\left(\mathrm{m}^{2} \mathrm{~s}\right)$ ). In fact, while the TOT analysis and its power law approximation show a comparable pattern, the experimental data reduction brings to light a curve concavity opposite to the convexity of the power law approximation curve. The lack of agreement in the initial combustion instants is due to transient effects in the earlier phases of the combustion process, related to the establishment of the reacting turbulent boundary layer (see discussion in Section 6). A comparison between timeresolved and TOT data is reported in Figure 7. Discrete TOT values of $r_{f}$ are in agreement with corresponding timeresolved data. The consistency check results for the HTPB baseline tests are shown in Tables 2 and 3. The percent variation between the different regression rate definitions are well below $5 \%$ for all presented tests, thus justifying the overall data handling procedure implemented in this work. In addition, the low variations in terms of mean regression rates show that the initial differences between the experimental data and their power law approximations do not lead to marked discrepancies in the mean values.

Finally, Figure 8 shows the actual trends of Re and $O / F$ in $G_{\text {ox }}$. The parameters needed for Re evaluation are defined by the experimental $O / F$ history during test. Note that the turbulent regime is lost for the low and final values of $G_{0 x}$ (say, $G_{\mathrm{ox}}<25$ ).

4.2. Effects of Metallized Additives. Once the HTPB baseline is fully characterized, it is possible to proceed with the evaluation of the ballistic characteristics of the innovative metallized formulations listed in Table 4. The same data handling procedure previously illustrated for HTPB was implemented yielding the experimental results shown in Figure 9 (nAl-containing formulations) and 10 (magnesium/boroncontaining formulations), and compared to HTPB baseline.

As one can see also from Table 5, most of the tested metallized formulations show an increase in regression rate,

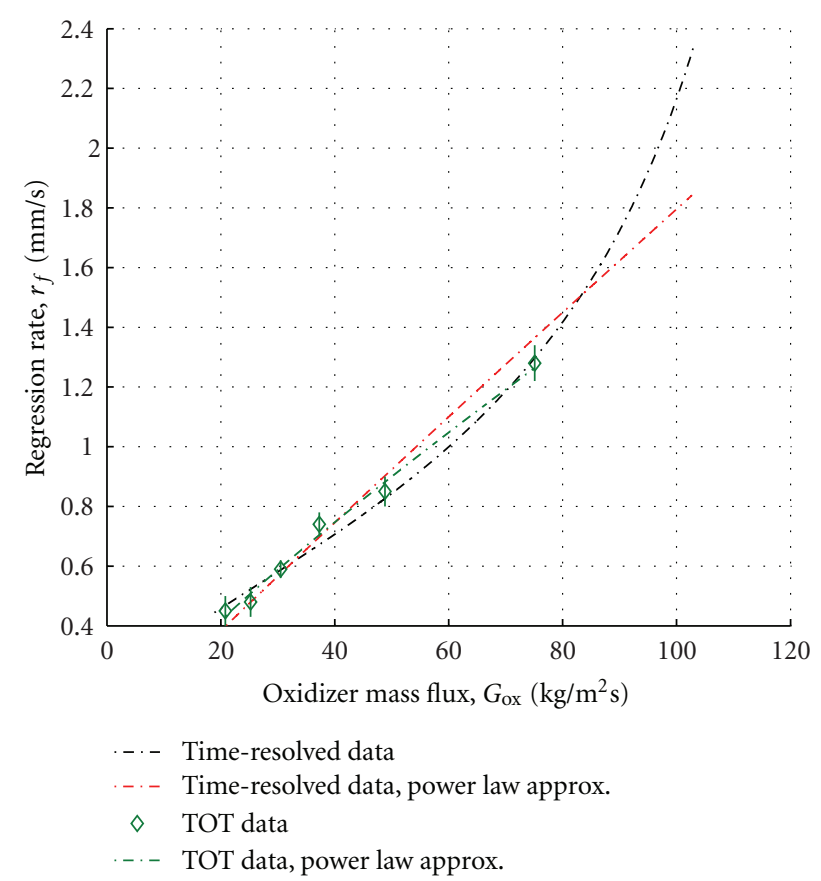

Figure 7: HTPB baseline, Test 3: example of experimental data $r_{f}\left(G_{\text {ox }}\right)$ and TOT analysis results showing the different paths and concavities characterizing the two techniques.

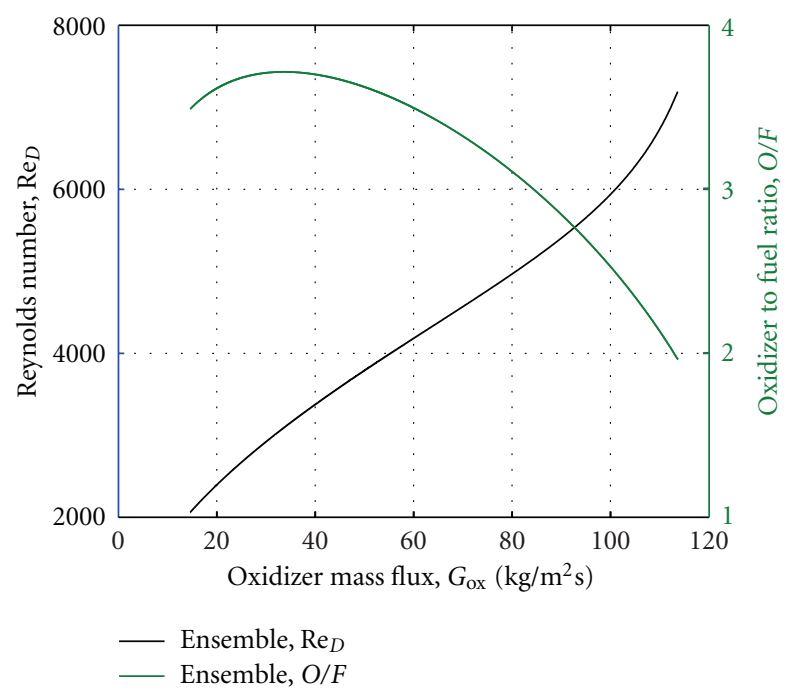

Figure 8: HTPB baseline: actual $\operatorname{Re}\left(G_{\text {ox }}\right)$ and $O / F\left(G_{\text {ox }}\right)$ for the ensemble average.

with respect to pure HTPB, especially in the initial combustion instants, when the oxidizer mass flux is maximum; in the final part of the combustion process the metallized formulations exhibit regression rates closer-and sometimes even lower-than the HTPB baseline. This trend is probably explained by the fact that metal combustion is favored by the high oxidizer mass flux and turbulence level at the beginning of the test. Table 6 presents the regression coefficients for the constant power law approximation of the loaded formulations, while the corresponding data for 
TABLE 2: HTPB baseline: optimization procedure comparing the initial regression rates $r_{f}\left(t_{\mathrm{ign}}\right)(13)$ and $r_{f_{i}}(14)$.

\begin{tabular}{lccc}
\hline Test number & $\begin{array}{c}\text { Regression rate at ignition }(13), \\
r_{f}\left(t_{\text {ign }}\right),(\mathrm{mm} / \mathrm{s})\end{array}$ & $\begin{array}{c}\text { Regression rate at ignition }(14), \\
r_{f_{i}},(\mathrm{~mm} / \mathrm{s})\end{array}$ & $\begin{array}{c}\text { Percent variation } \\
r_{f_{i}}-r_{f}\left(t_{\text {ign }}\right) r_{f_{i}}\end{array}$ \\
\hline 1 & 1.424 & 1.436 & 0.8 \\
2 & 2.389 & 2.390 & 0.1 \\
3 & 2.334 & 2.337 & 0.1 \\
4 & 1.319 & 1.323 & 0.3 \\
5 & 2.092 & 2.102 & 0.5 \\
6 & 1.506 & 1.509 & 0.2 \\
\hline
\end{tabular}

TABLE 3: HTPB baseline: optimization procedure. Comparison between the two different techniques implemented to obtain the experimental mean regression rate.

\begin{tabular}{lccc}
\hline \multirow{2}{*}{ Test number } & $\begin{array}{c}\text { Overall TOT regression rate }(9), \\
\bar{r}_{f \text { TOT }},(\mathrm{mm} / \mathrm{s})\end{array}$ & $\begin{array}{c}\text { Integral time-average regression rate }(10), \\
\bar{r}_{f},(\mathrm{~mm} / \mathrm{s})\end{array}$ & $\begin{array}{c}\text { Percent variation } \bar{r}_{f \text { TOT }}-\bar{r}_{f} \\
\% \bar{r}_{f \text { TOT }}\end{array}$ \\
\hline 1 & 0.715 & 0.747 & 4.4 \\
2 & 0.659 & 0.656 & 0.4 \\
3 & 0.682 & 0.690 & -1.0 \\
4 & 0.616 & 0.632 & -2.6 \\
5 & 0.662 & 0.676 & -2.1 \\
6 & 0.737 & 0.760 & -3.0 \\
\hline
\end{tabular}

HTPB baseline are presented in Figure 6: the metal-loaded formulations show a great sensibility to the oxidizer mass flux variation, due to the occurrence of more complex phenomena than convection, as proven by the presence of exponent values greater than 1 .

Contrary to expectations, coated L-ALEX showed lower regression than the uncoated ALEX, matching the baseline results. This behavior may be due to the fact that the coating process took place after the formation of cohesion clusters, thus involving groups of particles and subsequently deteriorating the powder characteristics. Literature sources also suggest that nonreactive coating layers do not radically modify the powder ignition temperature. Among the $\mathrm{nAl}$ augmented formulations, the one loaded with uncoated ALEX and carbon showed the highest increase in regression rate compared to the baseline, probably due to the great reactivity of ALEX and the simultaneous contribution of carbon to good powder dispersion in the matrix. In addition, carbon tends to reduce the thermal radiation penetration, hence avoiding decrease in regression rate results. Addition of $\mathrm{TiO}_{2}$ to ALEX-loaded formulations shows a lower regression rate under low oxidizer mass flux, with a marked increase in regression rate under higher fluxes.

Addition of $\mathrm{Mg}$ or $\mathrm{MgH}_{2}$ to ALEX-loaded formulations produced comparable results in increasing the regression rate, but without reaching the same results as the ALEX/carbon formulation. Results obtained for the formulations containing $\mathrm{Mg}$ or Boron, are shown in Figure 10. The first visible difference from the ALEX-containing ones is that, in this case, regression rates are faster than those of the baseline even under low levels of the oxidizer mass flux. Furthermore, one can see that the $\mathrm{MgB}$ compound is able to effectively overcome the well-known boron ignition problems. Indeed, the formulation containing only $\mathrm{MgB}$ shows the best ballistic response, with a remarkable increase in regression rate, particularly under high oxidizer mass flux. As expected, magnesium hydride does not show impressive ballistic properties, thus supporting the experimental evidence regarding its reactivity with HTPB and the subsequent rheological properties change of the polymeric matrix. In particular, the addition of $\mathrm{MgH}_{2}$ tends to worsen the characteristics of MgB-loaded formulations, enhancing its ignition problems and therefore decreasing its regression rate under high oxidizer mass flux. The simple addition of $\mathrm{MgH}_{2}$ (in different percents) and the addition of $\mathrm{Mg}$ and $\mathrm{MgB}$ lead to comparable intermediate results: anyway, it seems to be preferable to add low percents of $\mathrm{MgH}_{2}$, in order to lessen the binder properties decline.

A comprehensive summary of the metallized formulations percent differences (both in terms of regression rate and fuel mass flow rate) compared to the baseline is presented in Table 5. One can verify that the formulations that show the highest improvement in regression rate under high values of the oxidizer mass flux are those loaded with ALEX/carbon and those loaded with $\mathrm{Mg}$ and/or MgB. But while Mgand $\mathrm{MgB}$-loaded formulations exhibit a regression rate improvement also under low flux levels, the one containing ALEX and carbon shows good properties only under the highest oxidizer mass flux levels, with rapidly decreasing regression rate and fuel mass flow rate in the final portion of the combustion run.

Figures 9 and 10 also show how the Mg- and MgBcontaining formulations combustions start earlier and therefore at greater oxidizer mass flux levels than ALEX. The initial regression rate is particularly high, thus explaining why those formulations are particularly interesting, but it does not appear in Table 5 for lack of comparable baseline and ALEX-containing formulations data. 
TABLE 4: Overview of the tested metal-loaded formulations.

\begin{tabular}{|c|c|c|c|}
\hline Formulation & Number of samples & Port diameter $(\mathrm{mm})$ & External sample diameter $(\mathrm{mm})$ \\
\hline HTPB + 10\% ALEX + 2\% C & 4 & 4 & 18 \\
\hline $\mathrm{HTPB}+10 \%$ ALEX $+2 \% \mathrm{TiO}_{2}$ & 6 & 4 & 18 \\
\hline $\mathrm{HTPB}+10 \%$ ALEX $+2 \% \mathrm{C}+2 \% \mathrm{Mg}$ & 3 & 4 & 18 \\
\hline HTPB + 10\% L-ALEX & 4 & 4 & 18 \\
\hline $\mathrm{HTPB}+2.5 \% \mathrm{MgH}_{2}+1.4 \% \mathrm{MgB}$ & 4 & 4 & 18 \\
\hline $\mathrm{HTPB}+2.5 \% \mathrm{MgH}_{2}$ & 4 & 4 & 18 \\
\hline $\mathrm{HTPB}+7.5 \% \mathrm{MgH}_{2}$ & 8 & 4 & 18 \\
\hline $\mathrm{HTPB}+5 \% \mathrm{MgH}_{2}+5 \%$ ALEX $+1 \% \mathrm{C}$ & 4 & 4 & 18 \\
\hline $\mathrm{HTPB}+2.27 \% \mathrm{Mg}+1.4 \% \mathrm{MgB}$ & 4 & 4 & 18 \\
\hline $\mathrm{HTPB}+2.8 \% \mathrm{MgB}$ & 2 & 4 & 18 \\
\hline
\end{tabular}

TABLE 5: Metal-loaded formulations: regression rate and fuel mass flow rate percent differences at discrete values of oxidizer mass flux, compared to baseline.

\begin{tabular}{|c|c|c|c|c|}
\hline \multicolumn{5}{|c|}{ Regression rate percent difference (\%) } \\
\hline \multirow[b]{2}{*}{ Formulation } & \multicolumn{4}{|c|}{ Oxidizer mass flux $\left(\mathrm{kg} /\left(\mathrm{m}^{2} \mathrm{~s}\right)\right)$} \\
\hline & 40 & 60 & 80 & 100 \\
\hline $\mathrm{HTPB}+2.5 \% \mathrm{MgH}_{2}$ & 8.25 & 16.47 & 25.39 & 37.19 \\
\hline $\mathrm{HTPB}+7.5 \% \mathrm{MgH}_{2}$ & 2.19 & 8.13 & 14.48 & 22.72 \\
\hline $\mathrm{HTPB}+2.8 \% \mathrm{MgB}$ & 31.90 & 37.00 & 42.33 & 49.10 \\
\hline $\mathrm{HTPB}+2.27 \% \mathrm{Mg}+1.4 \% \mathrm{MgB}$ & 28.63 & 33.53 & 38.67 & 45.19 \\
\hline $\mathrm{HTPB}+2.5 \% \mathrm{MgH}_{2}+1.4 \% \mathrm{MgB}$ & 19.70 & 20.55 & 21.42 & 22.48 \\
\hline $\mathrm{HTPB}+10 \%$ ALEX + 2\% C & -22.57 & 3.58 & 38.87 & - \\
\hline $\mathrm{HTPB}+10 \%$ ALEX $+2 \% \mathrm{TiO}_{2}$ & -32.49 & -23.31 & -12.80 & 1.96 \\
\hline HTPB + 10\% L-ALEX & -11.82 & -5.12 & 2.14 & - \\
\hline $\mathrm{HTPB}+10 \%$ ALEX $+2 \% \mathrm{C}+2 \% \mathrm{Mg}$ & -0.15 & 15.90 & 34.67 & 61.67 \\
\hline $\mathrm{HTPB}+5 \% \mathrm{MgH}_{2}+5 \%$ ALEX $+1 \% \mathrm{C}$ & -7.06 & 9.44 & 29.03 & - \\
\hline
\end{tabular}

Fuel mass flow rate percent difference $(\%)$

Oxidizer mass flux $\left(\mathrm{kg} /\left(\mathrm{m}^{2} \mathrm{~s}\right)\right)$

\begin{tabular}{|c|c|c|c|c|}
\hline Formulation & 40 & 60 & 80 & 100 \\
\hline $\mathrm{HTPB}+2.5 \% \mathrm{MgH}_{2}$ & 9.31 & 17.62 & 26.63 & 38.54 \\
\hline $\mathrm{HTPB}+7.5 \% \mathrm{MgH}_{2}$ & 5.09 & 11.21 & 17.73 & 26.21 \\
\hline $\mathrm{HTPB}+2.8 \% \mathrm{MgB}$ & 34.20 & 39.39 & 44.82 & 51.70 \\
\hline $\mathrm{HTPB}+2.27 \% \mathrm{Mg}+1.4 \% \mathrm{MgB}$ & 31.16 & 36.16 & 41.40 & 48.05 \\
\hline $\mathrm{HTPB}+2.5 \% \mathrm{MgH}_{2}+1.4 \% \mathrm{MgB}$ & 21.79 & 22.66 & 23.54 & 24.63 \\
\hline $\mathrm{HTPB}+10 \%$ ALEX + $2 \% \mathrm{C}$ & -16.51 & 11.69 & 49.74 & - \\
\hline $\mathrm{HTPB}+10 \%$ ALEX $+2 \% \mathrm{TiO}_{2}$ & -26.51 & -16.52 & -5.08 & 10.99 \\
\hline HTPB + 10\% L-ALEX & -5.65 & 1.52 & 9.28 & - \\
\hline $\mathrm{HTPB}+10 \%$ ALEX $+2 \% \mathrm{C}+2 \% \mathrm{Mg}$ & 9.35 & 26.91 & 47.47 & 77.04 \\
\hline $\mathrm{HTPB}+5 \% \mathrm{MgH}_{2}+5 \%$ ALEX $+1 \% \mathrm{C}$ & -1.67 & 15.78 & 36.51 & - \\
\hline
\end{tabular}

Finally, the effects of the ignition delay optimization procedure are shown in Figures 11 and 12: it is possible to see the consistent behavior of the various tested formulations and how almost all the data are comprised in a narrow range of times and oxidizer mass fluxes.

\section{Effects of Radiant Heat Transfer}

As recalled in Section 2, the recognized reference for hybrid rocket combustion is the diffusion-limited, purely convective ballistic model proposed by Marxman et al. [3, 4]. Data collected during this experimental investigation show that the power law relationship for $r_{f}\left(G_{\mathrm{ox}}\right)$ identified by Marxman and coworkers is not fully consistent with the trend of instantaneous time-resolved data. The latter exhibits a different concavity with respect to its power law approximation, yielding a markedly larger $r_{f}$ for high $G_{\mathrm{ox}}$ values (see Figure 6). This effect was reported also by Evans et al. during similar investigation on HREs combustion [2729]. On the other hand, approximation of time-resolved data reported in Figure 6 shows $r_{f} \propto G_{\mathrm{ox}}^{0.7}$.

Next, how important might be radiation in reproducing the obtained experimental results and explaining the previously mentioned differences was investigated. The original 
TABLE 6: Additivated formulations: coefficients and uncertainties for constant power law approximation of the regression rate. For baseline data, see Figure 6.

\begin{tabular}{lccc}
\hline Formulation & $a_{r}$ & $n_{r}$ \\
\hline $\mathrm{HTPB}+2.5 \% \mathrm{MgH}_{2}$ & $0.031 \pm 0.001$ & $0.901 \pm 0.005$ & 0.956 \\
$\mathrm{HTPB}+7.5 \% \mathrm{MgH}_{2}$ & $0.028 \pm 0.001$ & $0.918 \pm 0.006$ & 0.940 \\
$\mathrm{HTPB}+2.8 \% \mathrm{MgB}$ & $0.002 \pm 0.001$ & $0.981 \pm 0.013$ & 0.897 \\
$\mathrm{HTPB}+2.27 \% \mathrm{Mg}+1.4 \% \mathrm{MgB}$ & $0.032 \pm 0.001$ & $0.930 \pm 0.006$ & 0.935 \\
$\mathrm{HTPB}+2.5 \% \mathrm{MgH}+1.4 \% \mathrm{MgB}$ & $0.043 \pm 0.001$ & $0.825 \pm 0.005$ & 0.946 \\
\hline $\mathrm{HTPB}+10 \% \mathrm{ALEX}+2 \% \mathrm{C}$ & $0.001 \pm 0.001$ & $1.687 \pm 0.008$ & 0.976 \\
$\mathrm{HTPB}+10 \% \mathrm{ALEX}+2 \% \mathrm{TiO}_{2}$ & $0.001 \pm 0.001$ & $1.639 \pm 0.009$ & 0.952 \\
$\mathrm{HTPB}+10 \% \mathrm{~L}-\mathrm{ALEX}$ & $0.026 \pm 0.001$ & $0.883 \pm 0.004$ & 0.972 \\
$\mathrm{HTPB}+10 \% \mathrm{ALEX}+2 \% \mathrm{C}+2 \% \mathrm{Mg}$ & $0.006 \pm 0.001$ & $1.272 \pm 0.006$ & 0.970 \\
$\mathrm{HTPB}+5 \% \mathrm{MgH}_{2}+5 \% \mathrm{ALEX}+1 \% \mathrm{C}$ & $0.013 \pm 0.001$ & $1.088 \pm 0.005$ & 0.971 \\
\hline
\end{tabular}

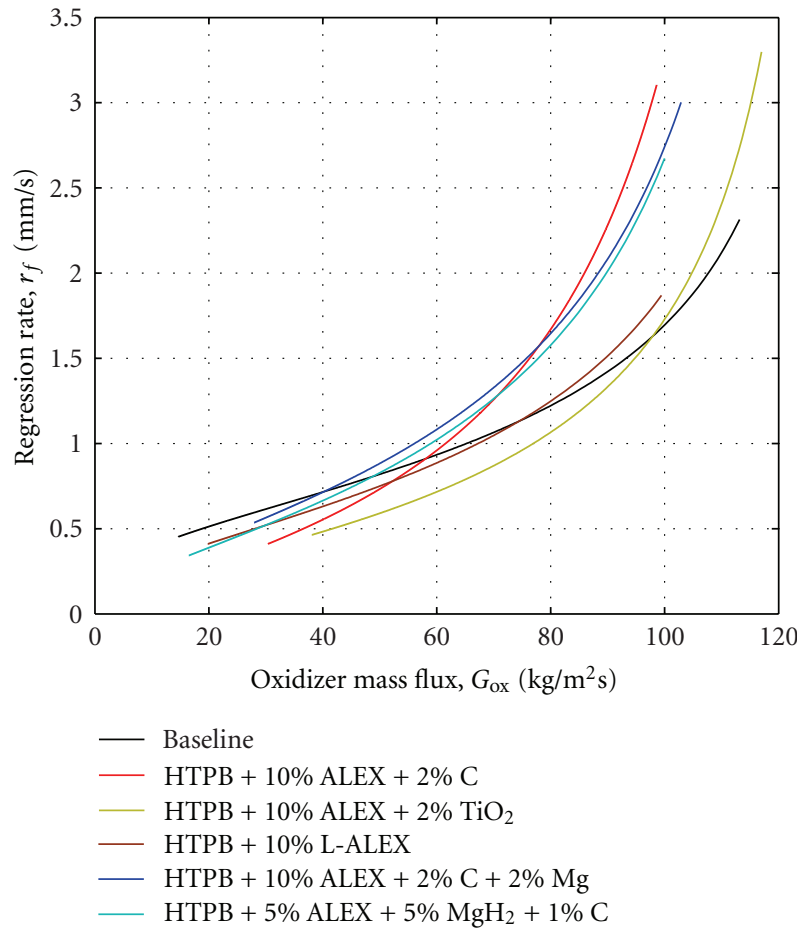

Figure 9: ALEX-loaded formulations: ensemble average, experimental data $r_{f}\left(G_{\text {ox }}\right)$ compared to baseline. Error bars are not reported to improve readability.

convective model requires modifications in order to include radiant heat flux contributions. To this purpose, the model proposed by Greatrix [30] was considered due to its simplified treatment of the reacting boundary layer with respect to the original work by Marxman and coworkers.

5.1. The Regression Rate Model by Greatrix. The model proposed by Greatrix aims at predicting the fuel regression rate, provided that the fundamental thermodynamic and fluid-dynamic properties are given. Starting point of the model is an energy balance at the gasifying fuel surface where only convective heat transfer is considered:

$$
\rho_{f} r_{f}\left[C_{s}\left(T_{s}-T_{i}\right)-\Delta H_{s}\right]=h\left(T_{f}-T_{s}\right) \text {. }
$$

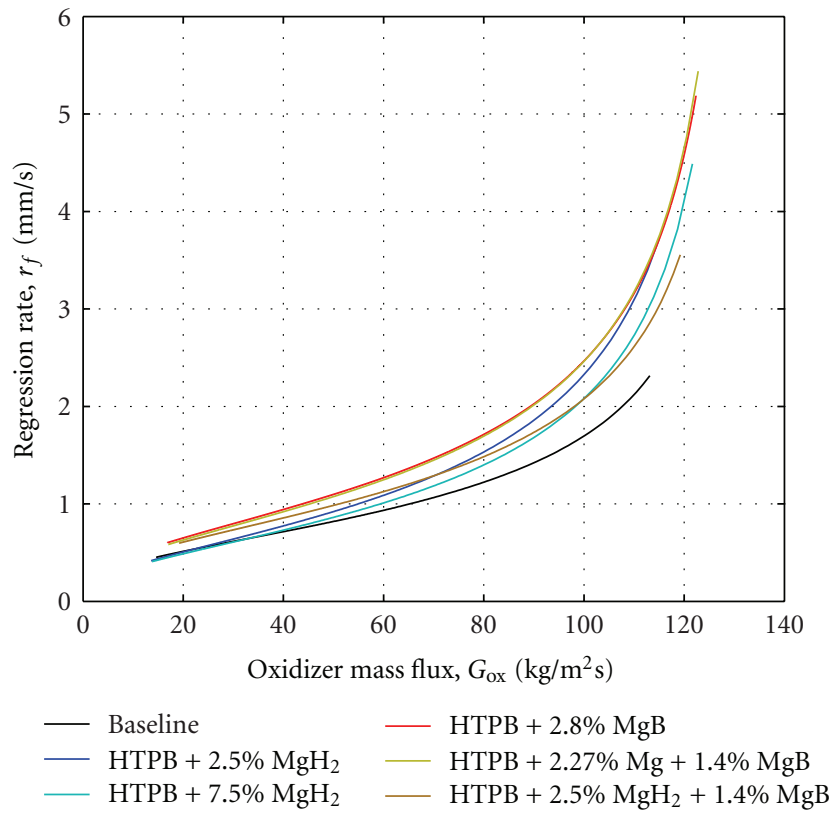

FIGURE 10: Magnesium-loaded formulations: ensemble average, experimental data $r_{f}\left(G_{\mathrm{ox}}\right)$ compared to baseline. Error bars are not reported to improve readability.

In (17), the overall $r_{f}$ can be considered as the fluxdepending regression, while the pressure-depending part can be neglected for hybrid systems; the convective fuel regression rate can thus be estimated as:

$$
r_{f}=\frac{h\left(T_{f}-T_{s}\right)}{\rho_{f}\left[C_{s}\left(T_{s}-T_{i}\right)-\Delta H_{s}\right]} .
$$

Changes of the thermodynamic and fluid-dynamic quantities are incorporated in the definition of the convective heat exchange coefficient, whereas all other parameters can be considered constant throughout the combustion process. The occurrence of gasified fuel blowing towards the reaction zone $[3,4]$ is taken into account thanks to

$$
h=\frac{\rho_{f} r_{f} C_{p}}{\exp \left(\rho_{s} r_{f} C_{p} / h^{*}\right)-1} .
$$




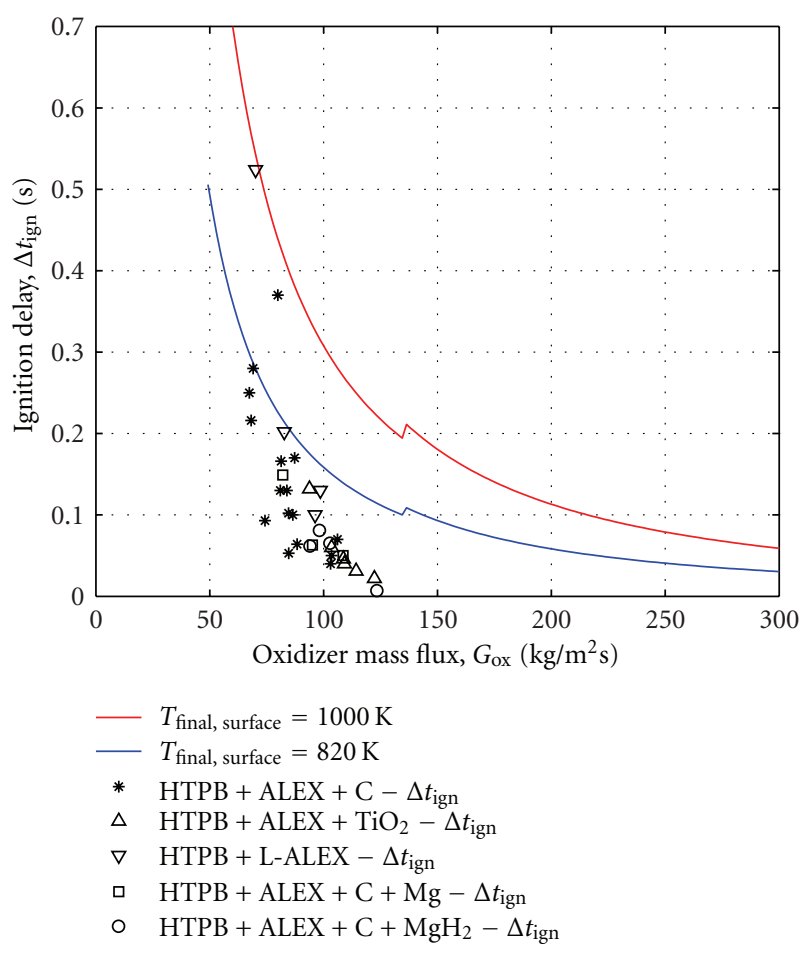

FIGURE 11: Ignition delay for aluminum-containing formulations. Comparison with the purely convective model by Ohlemiller and Summerfield [19], for two different final surface temperatures [25, 26].

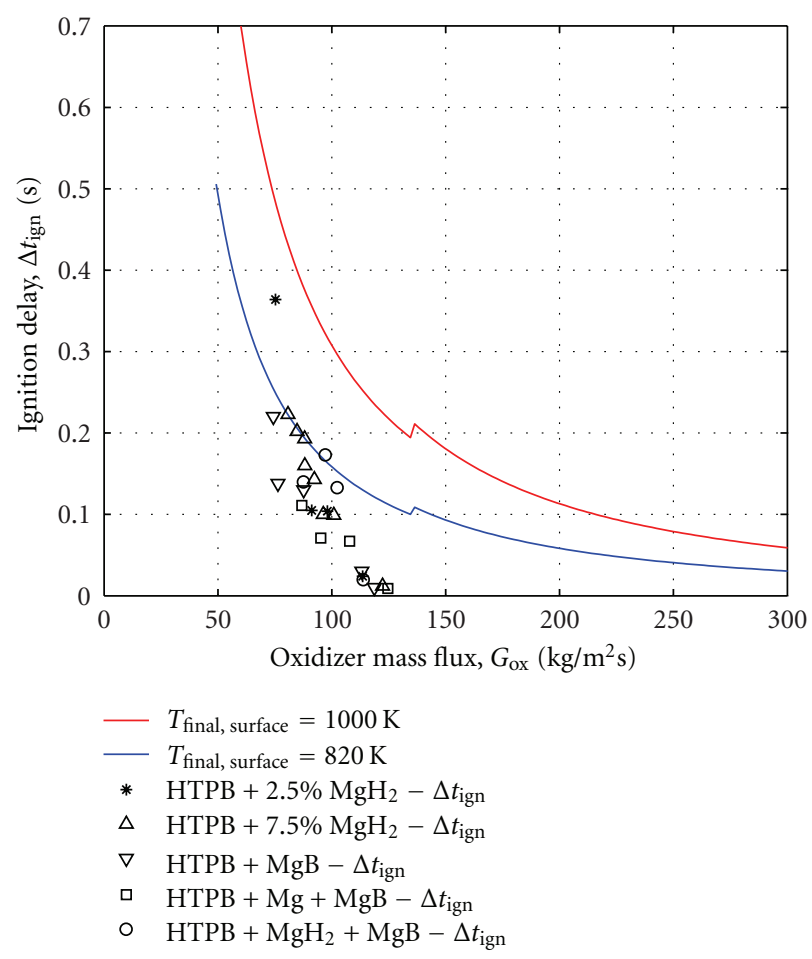

FIGURE 12: Ignition delay for magnesium-containing formulations. Comparison with the purely convective model by Ohlemiller and Summerfield [19], for two different final surface temperatures [25, 26].
From the Reynolds analogy, coupled with the definition of the Darcy-Weisbach friction factor (calculated with the Colebrook semiempirical correlation as reported in [20]), one obtains

$$
\left(f^{*}\right)^{-1 / 2}=-2 \log _{10}\left[\frac{2.51}{\operatorname{Re}_{d}\left(f^{*}\right)^{1 / 2}}+\frac{\epsilon / d}{3.7}\right] .
$$

Therefore, the convective heat exchange coefficient without blowing can be evaluated as

$$
h^{*}=\frac{k^{2 / 3} C_{p}^{1 / 3} G \cdot f^{*}}{\mu^{2 / 3} \cdot 8} .
$$

The implicit (20), depending on the instantaneous values of the fluid-dynamic properties, can be resolved with the Newton numerical method; for HTPB-based fuels, the duct roughness $\epsilon$ is defined equal to $5 \mu \mathrm{m}$ [30]. The regression rate can thus be defined as

$$
r_{f}=\frac{h^{*}}{\rho_{s} C_{p}} \ln \left[1+\frac{\left(T_{f}-T_{s}\right)}{\left(T_{s}-T_{i}-\Delta H_{s} / C_{s}\right)}\right] .
$$

5.2. Extending the Regression Rate Model by Greatrix. In this section the work done to extend the original Greatrix model is discussed.

\subsubsection{Effective Values of Thermodynamic and Transport} Properties. The thermodynamic and transport properties of (22) require a proper evaluation. In particular, in the original Greatrix model, $T_{f}, k, \mathrm{C}_{p}$, and $\mu$ are defined by values close to the ones characterizing the stoichiometric condition for the considered propellants. In the present study, a phenomenological approach is chosen for the $r_{f}$ determination. Experimental, time-resolved data are considered as input for evaluating the effective values of thermodynamic and transport properties. In particular, experimental $\bar{D}(t)$ and $O / F(t)$ are considered. For each time-step of the combustion process, the associated $O / F$ is used to determine the effective values of $T_{f}, k, \mathrm{C}_{p}$, and $\mu$, by thermochemical calculations by the NASA CEA code. As shown in Figure 8, the overall $O / F$ exhibits values in the range from 1 to 4.5 under the investigated conditions. For the determination of the parameters defining $h^{*}(21)$, knowing the histories of $\bar{D}(t)$ and $O / F(t)$ enables evaluating the histories of $\operatorname{Re}_{D}$, and $f^{*}$ (20) and (21).

The term $\Delta H_{s}$ appearing in (22) is defined according to literature data. As suggested by Lengellé et al., the net surface enthalpy is defined equal to $-430 \mathrm{cal} / \mathrm{g}$, [25]. This datum refers to the degradation process of reference HTPB. Surface temperature is considered equal to $820 \mathrm{~K}$, from a previous work of Risha et al. on HTPB burning under pure oxygen [31]. In this first effort, the same values of $\Delta H_{s}$ and $T_{s}$ were used for modeling of loaded formulations, in spite of the possible changes induced by energetic additives.

5.2.2. Radiant Heat Transfer Contributions. The experimental correlations available in the literature were reviewed. 
In particular, Chiaverini et al. $[13,32]$ and Risha et al. $[9,31]$ reported detailed analyses comparing theoretical and experimental results. These approaches, while very promising and sufficiently accurate, in general are not valid for every formulation under every operating condition. Within this framework, the radiant heat transfer contribution was estimated for a variety of sources spanning from the gaseous combustion products to soot formation from the polymeric binder and to metal particulate dispersed in the gaseous phase. Indepth conduction in the solid fuel grain was not considered in this study.

The flame zone can be considered a source of thermal radiation, while the adjoining areas are not taken into account, as proposed by [13]: indeed, the flame zone represents the highest temperature zone in the gaseous flow and in the diffusion zone, where the highest concentration of gaseous combustion products $\left(\mathrm{CO}_{2}, \mathrm{CO}\right.$, and $\left.\mathrm{H}_{2} \mathrm{O}\right)$ can be detected. The emissivity of burnt gases can be determined according to (23), where $\Delta \epsilon$ is the negative contribution due to the possible overlapping of emissivity bands of $\mathrm{CO}_{2}$ and $H_{2}[13]$ :

$$
\epsilon_{\mathrm{gas}}=\epsilon_{\mathrm{H}_{2} \mathrm{O}}+\epsilon_{\mathrm{CO}_{2}}+\epsilon_{\mathrm{CO}}-\Delta \epsilon
$$

A first correlation taking into account the radiant heat transfer due to combusted gases can thus be identified, as originally proposed by Marxman and coworkers to correct their purely convective model [3]:

$$
q_{r, g}^{\prime \prime}=\sigma \epsilon_{s}\left(\epsilon_{g} T_{f}^{4}-\alpha_{g} T_{s}^{4}\right),
$$

where according to $[13,33]$ :

(i) $\epsilon_{s}=0.95$;

(ii) $\epsilon_{g}=1 \cdot 10^{-2}-4 \cdot 10^{-2}$;

(iii) $\alpha_{g} \cong \epsilon_{g}$.

Gas emissivity, according to [13], can be approximated as linearly varying from $1 \cdot 10^{-2}$ to $4 \cdot 10^{-2}$ in the range of $1.5 \leq O / F \leq 2.5$, while maintaining the highest value for $O / F>2.5$.

Due to the large difference between surface temperature and flame temperature, it is plausible to suppose that radiant heat transfer towards the flame is negligible.

An alternative model for the gas-phase radiation was proposed by Strand et al. [11]. In this latter work, an explicit contribution from pressure was included as

$$
q_{r, g}^{\prime \prime}=\sigma T_{g}^{4}\left(1-e^{k_{g} \cdot p_{c} \cdot D}\right)
$$

In (25), the gas absorption coefficient is defined as reported in (26)

$$
k_{g}=9.33 \cdot 10^{-4}-6.19 \cdot 10^{-6} \cdot p_{c}+1.79 \cdot 10^{-8} \cdot p_{c}^{2} .
$$

Since, under the investigated conditions, $p_{c}$ exerts a limited influence on $r_{f}$, in spite of the explicit pressure dependence, (25) is not considered very relevant.
It is important to point out that the main radiant heat source, about $80 \%$ of the total value, is due to soot (partially unburned solid fuel particles in the gas phase). An approximation of this contribution [7, 13], considering experimental data, is given as

$$
q_{r, \text { soot }}^{\prime \prime}=\sigma T_{g}^{4}\left(1-e^{k_{s}}\right) .
$$

In the latter (27), the soot absorption coefficient can be defined as

$$
k_{s}=0.51-0.113 \frac{O}{F}, \quad\left(1.5 \leq \frac{O}{F} \leq 3.5\right),
$$

where the absence of pressure dependences and the appearance of an explicit dependence on $O / F$ can be noted.

For Al-containing formulations, an additional radiant heat flux emission is defined taking into account the radiation effects due to the presence of $\mathrm{Al} / \mathrm{Al}_{2} \mathrm{O}_{3}$ particles [28]:

$$
q_{r, \mathrm{Al}}^{\prime \prime}=\sigma \epsilon_{\mathrm{Al} / \mathrm{Al}_{2} \mathrm{O}_{3}}\left(T_{b}^{4}-T_{s}^{4}\right) .
$$

In (29), $T_{b}$ is the boiling temperature of aluminum $(2792 \mathrm{~K})$ and the emissivity of $\mathrm{Al} / \mathrm{Al}_{2} \mathrm{O}_{3}$ is taken equal to 0.1 , [34].

5.3. Extended Greatrix Regression Rate Model. The original purely convective Greatrix model was extended to include radiation effects by writing the surface energy balance of (17) as

$$
\rho_{s} r_{f}\left[C_{s}\left(T_{s}-T_{i}\right)-\Delta H_{s}\right]=h\left(T_{f}-T_{s}\right)+q_{r}^{\prime \prime} .
$$

The radiant heat flux term $q_{r}^{\prime \prime}$ refers to the sum of several single contributions defined in Section 5.2.2. As for thermodynamic and thermal properties, also the radiant heat transfer terms for combustion gases and soot are evaluated for each time step of the burning process, considering the experimental $O / F$ history as input. Under the considered circumstances, the extended phenomenological model of the regression rate gives

$$
r_{f}=\frac{h\left(T_{f}-T_{s}\right)+q_{r}^{\prime \prime}}{\rho_{s}\left[C_{s}\left(T_{s}-T_{i}\right)-\Delta H_{s}\right]} .
$$

This latter form was implemented for the time-resolved ballistic analysis as shown in the next section.

\section{Results}

Three different fuel formulations are considered in this part of the study: HTPB baseline, HTPB loaded with $2 \% \mathrm{C}$ and $10 \%$ ALEX, and HTPB loaded with 2.8\% MgB90 (20\% Mg). The three fuel formulations are characterized by different contributions to the radiant heat flux. In particular, for all of the tested formulations the combustion gases and soot contributions given by (24) and (27) are present. Under the investigated conditions, the latter (27) is considered valid 


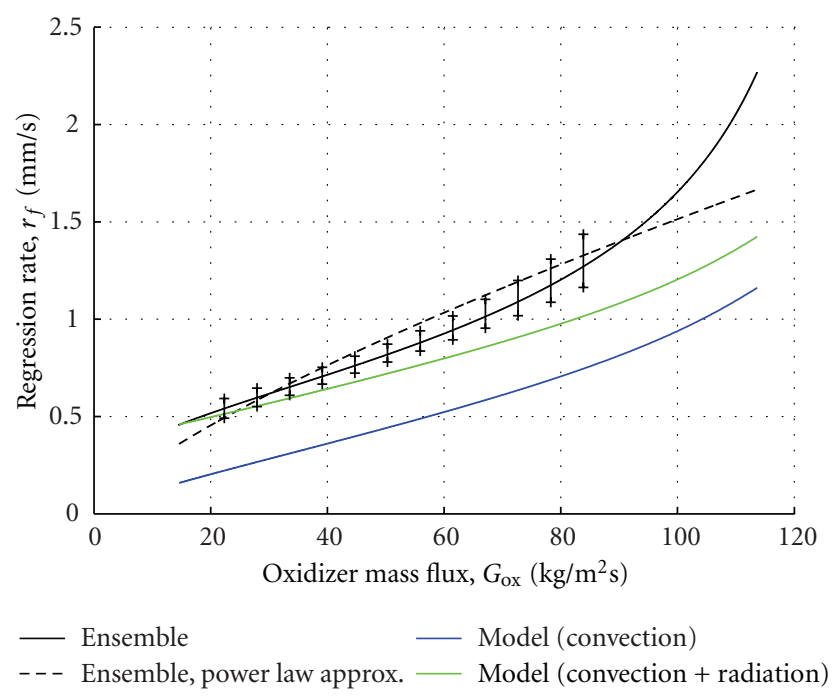

FIGURE 13: HTPB baseline: ensemble average of experimental data for $r_{f}\left(G_{\text {ox }}\right)$ with its power law approximation and extended Greatrix model.

over the tested $O / F$ range. When dealing with HTPB loaded with ALEX, the additional term accounting for emissivity of $\mathrm{Al} / \mathrm{Al}_{2} \mathrm{O}_{3}$ particles (29) is considered.

Overall, the results obtained show a quite different behavior from the original purely convective model.

In Figure 13, the results achieved for HTPB baseline considering a pure convection regime and the extended model (31) are reported in terms of $r_{f}\left(G_{\text {ox }}\right)$. Time-resolved instantaneous, ensemble average $r_{f}$ and its power law approximation are reported in the same Figure 13. Resorting to the effective values of thermal and transport properties yields $r_{f}\left(G_{\text {ox }}\right)$ curves with a similar concavity with respect to the experimental data for both convective and extended models. This result is unlikely by a conventional approach based on fixed values of thermal and transport properties. Considering the radiant heat transfer term, the $r_{f}\left(G_{\mathrm{ox}}\right)$ behavior provides a better representation of the experimental data, in spite of a marked difference for $G_{\mathrm{ox}} \geq 100 \mathrm{~kg} /\left(\mathrm{m}^{2} \mathrm{~s}\right)$. In this region one can speculate about possible transient effects due to the development of the reacting boundary layer, determining a marked regression rate increase, such as high oxidizer mass flux, high turbulence level, and probably other reasons as well.

The results concerning the $r_{f}\left(G_{\text {OX }}\right)$ response including radiant heat transfer for HTPB loaded with ALEX and MgB90 (20\% Mg) are reported in Figures 14 and 15 respectively. For these formulations, the extended Greatrix model shows a good agreement in $r_{f}\left(G_{\mathrm{ox}}\right)$ with experimental data but limited to the low $G_{\text {ox }}$ region.

Differences between experimental and model results for metallized formulations are mainly related to the assumption of the same $\Delta H_{s}$ value used for HTPB baseline. Loading the solid fuel grain with metals enhance solid fuel reactivity. An evidence of this is the reduced ignition delay of metallized fuel formulations with respect to HTPB baseline (see Figures 3,11 , and 12). As a consequence of the enhanced reactivity,

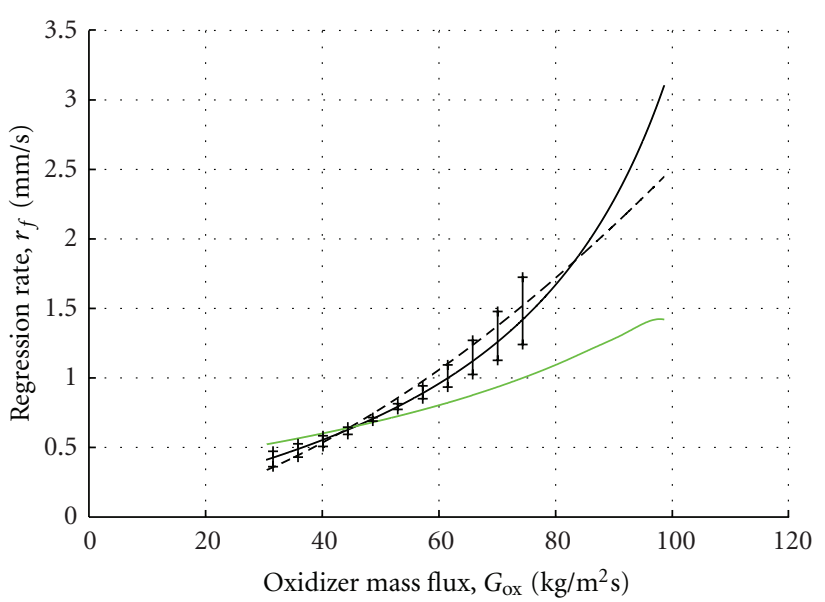

Ensemble
- - Ensemble, power law approx.

Figure 14: HTPB, loaded with ALEX and Carbon: ensemble average of experimental data for $r_{f}\left(G_{\mathrm{ox}}\right)$ with its power law approximation and extended Greatrix model.

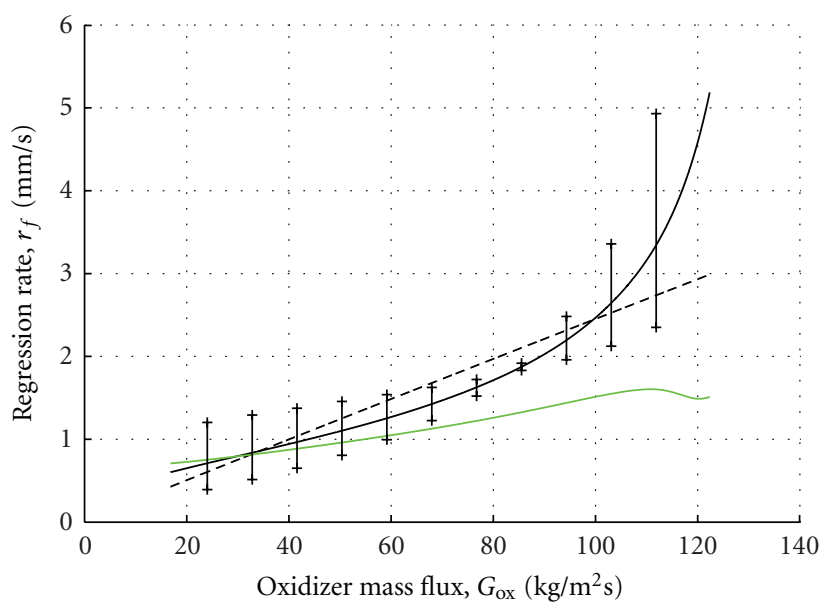

- Ensemble
-- Ensemble, power law approx.

FIGURE 15: HTPB, loaded with MgB90 (20\% Mg): ensemble average of experimental data for $r_{f}\left(G_{\mathrm{ox}}\right)$ with its power law approximation and extended Greatrix model. Note model $r_{f}$ results for $G_{\mathrm{ox}} \geq 100$ $\mathrm{kg} /\left(\mathrm{m}^{2} \mathrm{~s}\right)$ exhibiting a non-monotonic trend.

particular attention should be given to $\Delta H_{s}$. This parameter should exhibit a less endothermic behavior for metal-loaded fuel formulations than inert binder, thus providing a $r_{f}$ increase with respect to the currently achieved behavior.

Model data for metallized fuel formulations, and notably MgB-loaded HTPB, exhibit nonmonotonic behavior of $r_{f}$ for decreasing $G_{0 x}$ in the earlier phases of the combustion. This result is mainly related to the marked nonmonotonic and nonlinear behavior of thermodynamic and transport properties for the relatively low $O / F$ values characterizing the initial phases of burning. 
In spite of the discussed effects, the proposed approach enable to define in all cases a $r_{f}\left(G_{\mathrm{Ox}}\right)$ curve characterized by a similar trend with respect to the experimental time-resolved data.

\section{Conclusions and Future Developments}

A systematic ballistic characterization of innovative HRE solid fuels was performed, by implementing an optical time-resolved technique able to provide the instantaneous regression rates and other relevant ballistic parameters. All experiments were conducted for HTPB-based solid fuels under GOX, with $p_{c}=10$ bar and $\dot{m}_{\mathrm{ox}}=1.67 \mathrm{~g} / \mathrm{s}$ (corresponding to an initial $G_{\text {ox }}=130 \mathrm{~kg} /\left(\mathrm{m}^{2} \mathrm{~s}\right)$ ), but extension to a wider set of operating conditions is already in progress. The performed measurements clearly point out that $r_{f}\left(G_{\mathrm{oX}}\right)$ exhibits a peculiar monotonic growth with $G_{\mathrm{ox}}$ (e.g., see Figure 5), whose power law approximation however features an exponent close to the 0.8 value predicted by Marxman [3, 4]. The performed measurements also show that adding ALEX or MgB to HTPB speeds up the regression rate of solid fuels especially under the highest oxidizer mass fluxes and turbulence levels.

The Greatrix convective regression rate model was revised and extended to include the actual $O / F$ history in time with the corresponding thermophysical properties of the burned mixture. Moreover, radiant flux contributions from both the hot gases and soot particles were accounted for HTPB-based formulations resorting to optical properties from the literature $[7,13]$. Considering radiant heat transfer, a better agreement between model results and experimental data is achieved in terms of $r_{f}$ for HTPB baseline, while metallized formulations still show discrepancies that will be addressed in future works.

Recommended developments are to determine experimentally radiant heat fluxes for high-energy ingredients under a wider set of operating conditions (e.g., extending the $G_{\mathrm{ox}}$ and $p_{c}$ ranges). Moreover, specific attention will be given to the value of $\Delta H_{s}$ needed to implement the extended model.

\section{Nomenclature}

\section{Abbreviations}

2D: Two-dimensional

ALEX: Aluminum exploded (100 nm, uncoated)

an: Analytical

B90: $\quad$ Boron with $90 \%$ purity

CEA: Chemical equilibrium with application

DOA: Dioctyl adipate

GOX: Gaseous oxygen

HRE: Hybrid rocket engine

HTPB: Hydroxyl-terminated polybutadiene

IPDI: Isophorone diisocyanate

L-ALEX: Aluminum exploded (100 nm, coated with palmitic acid)

MgB: Magnesium-boron composite

nAl: $\quad$ Nanosized aluminum
NASA: National Aeronautics and Space Administration

OD: $\quad$ Outer diameter, $\mathrm{mm}$

$\mathrm{Re}_{D}$ : Reynolds number (based on diameter)

TIN: Dibutyltin diacetate

TOT: Thickness over time

wrt: With reference to.

\section{Chemical Symbols}

$\begin{array}{ll}\text { Al: } & \text { Aluminum } \\ \text { B: } & \text { Boron } \\ \mathrm{C}: & \text { Carbon } \\ \mathrm{Mg}: & \text { Magnesium } \\ \mathrm{MgH}_{2}: & \text { Magnesium hydride } \\ \mathrm{TiO}_{2}: & \text { Titanium oxide. }\end{array}$

\section{Latin Symbols}

$a_{D}: \quad$ Multiplier factor in (2)

$A_{f}: \quad$ Port regressing surface area, $\mathrm{mm}^{2}$

$C_{p}$ : Constant pressure specific heat (gas phase),

$\mathrm{J} / \mathrm{kg} \cdot \mathrm{K}$

$C_{s}: \quad$ Solid phase specific heat, $\mathrm{J} / \mathrm{kg} \cdot \mathrm{K}$

D: $\quad$ Diameter, $\mathrm{mm}$

$D_{0}$ : Nominal initial port diameter, $\mathrm{mm}$

$\bar{D}: \quad$ Space-average mean diameter, $\mathrm{mm}$

$\bar{D}_{\text {end }}$ : Space-average diameter at measurement completion, $\mathrm{mm}$

$\bar{D}_{\text {ign }}:$ Space-average diameter at ignition, $\mathrm{mm}$

$\bar{D}_{i}$ : $\quad$ Sampled space-average diameter (ith value), mm

$f^{*}$ : Friction factor without blowing

G: $\quad$ Total mass flux, $\mathrm{kg} /\left(\mathrm{m}^{2} \cdot \mathrm{s}\right)$

$G_{f}: \quad$ Fuel mass flux, $\mathrm{kg} /\left(\mathrm{m}^{2} \mathrm{~s}\right)$

$G_{\text {ox }}:$ Oxidizer mass flux, $\mathrm{kg} /\left(\mathrm{m}^{2} \mathrm{~s}\right)$

$h$ : Convective heat transfer coefficient with blowing, $\mathrm{W} /\left(\mathrm{m}^{2} \cdot \mathrm{K}\right)$

$h^{*}$ : Convective heat transfer coefficient without blowing, $\mathrm{W} /\left(\mathrm{m}^{2} \cdot \mathrm{K}\right)$

$k$ : $\quad$ Conductive heat transfer coefficient (of the gas

phase $), \mathrm{W} /(\mathrm{m} \cdot \mathrm{K})$

$k_{g}$ : Gas absorption coefficient

$k_{s}$ : $\quad$ Soot absorption coefficient

$L_{s}: \quad$ Fuel sample length, mm

$\dot{m}_{f}$ : Fuel mass flow rate, $\mathrm{g} / \mathrm{s}$

$\dot{m}_{\mathrm{ox}}$ : Oxidizer mass flow rate, $\mathrm{g} / \mathrm{s}$

$n_{D}: \quad$ Time exponent in (2)

$\mathrm{O} / \mathrm{F}: \quad$ Oxidizer-to-fuel ratio

$p_{c}$ : Chamber pressure, bar

$q_{r, \mathrm{Al}}^{\prime \prime}:$ Radiant heat flux due to $\mathrm{Al} / \mathrm{Al}_{2} \mathrm{O}_{3}, \mathrm{~W} / \mathrm{m}^{2}$

$q_{r, g}^{\prime \prime}:$ Radiant heat flux due to burnt gases, $\mathrm{W} / \mathrm{m}^{2}$

$q_{r, \text { soot }}^{\prime \prime}:$ Radiant heat flux due to soot, $\mathrm{W} / \mathrm{m}^{2}$

$r_{f}: \quad$ Regression rate, $\mathrm{mm} / \mathrm{s}$

$\left\langle r_{f}\right\rangle$ : Time-average regression rate, $\mathrm{mm} / \mathrm{s}$

$r_{f_{i}}$ : Measurement initial regression rate, $\mathrm{mm} / \mathrm{s}$

$r_{u}$ : Mass flux-depending regression rate, $\mathrm{mm} / \mathrm{s}$

$R^{2}$ : Correlation index

$t$ : Time, $s$ 
$t_{i}$ : Sampling time ( $i$ th value), $s$

$t_{0}$ : Reference time in (2), $\mathrm{s}$

$t_{\text {end }}$ : Measurement completion time, s

$t_{\text {ign }}$ : Ignition time, $\mathrm{s}$

$T_{b}$ : Boiling temperature, $\mathrm{K}$

$T_{i}$ : Initial fuel temperature, $\mathrm{K}$

$T_{f}$ : Flame temperature, $\mathrm{K}$

$T_{g}$ : Gas temperature, $\mathrm{K}$

$T_{s}$ : Fuel surface temperature, $\mathrm{K}$.

\section{Greek Symbols}

$\alpha: \quad$ Thermal diffusivity $\mathrm{m}^{2} / \mathrm{s}$

$\alpha_{g}: \quad$ Gas phase adsorption coefficient

$\Delta H_{s}$ : Solid-phase vaporization enthalpy balance, $\mathrm{cal} / \mathrm{g}$

$\epsilon: \quad$ Regressing surface roughness, $\mu \mathrm{m}$

$\epsilon_{\mathrm{Al} / \mathrm{Al}_{2} \mathrm{O}_{3}}: \mathrm{Al} / \mathrm{Al}_{2} \mathrm{O}_{3}$ emissivity, $\mathrm{W} / \mathrm{m}^{2}$

$\epsilon_{s}: \quad$ Solid-phase emissivity

$\epsilon_{g}: \quad$ Gas-phase emissivity

$\mu: \quad$ Gas-phase viscosity, $\mathrm{kg} /(\mathrm{m} \cdot \mathrm{s})$

$\rho_{f}: \quad$ Solid fuel density, $\mathrm{kg} / \mathrm{cm}^{3}$

$\sigma: \quad$ Stefan-Boltzmann constant, $\mathrm{W} /\left(\mathrm{m}^{2} \cdot \mathrm{K}^{4}\right)$.

\section{Acknowledgments}

This work was partially supported by ORPHEE (Operational Research Project on Hybrid Engine in Europe), European FP7 Program. Theme 9: Space, Area: SPA-2007.2.2.02-Space Transportation, Grant Agreement 218830 and SPARTAN (SPAce exploration Research for Throttleable Advanced eNgine), Research Area: SPA.2010.2.1-04-Space Transportation for Space Exploration. MACH I (King of Prussia, PA, USA) and Advanced Powder Technology LLC (Tomsk, Russia) are acknowledged for the supplied materials and the precious collaboration.

\section{References}

[1] L. T. de Luca, Energetic Problems in Aerospace Propulsion, chapter 12, Politecnico di Milano, 1st edition, 2007.

[2] G. P. Sutton, Rocket Propulsion Elements, John Wiley \& Sons, 6th edition, 1992.

[3] G. Marxman and M. Gilbert, "Turbulent boundary layer combustion in the hybrid rocket," Symposium (International) on Combustion, vol. 9, no. 1, pp. 371-383, 1963.

[4] G. A. Marxman, "Fundamentals of hybrid boundary layer combustion," in Heterogeneous Combustion Conference, December 1963.

[5] D. Altman, "Highlights in hybrid rocket propulsion," in Proceedings of the 10th International Workshop on Combustion and Propulsion, p. 17, Lerici La Spezia, Italy, September 2003.

[6] D. Altman and A. Holzmann, "Overview and history of hybrid rocket propulsion," in Fundamentals of Hybrid Rocketcombustion and Propulsion, M. J. Chiaverini and K. K. Kuo, Eds., vol. 218, chapter 1, pp. 1-36, AIAA Progress in Astronautics and Aeronautics, 2007.

[7] M. J. Chiaverini and K. K. Kuo, Fundamentals of Hybrid Rocket Combustion and Propulsion, AIAA, 2006.
[8] R. A. Yetter, G. A. Risha, and S. F. Son, "Metal particle combustion and nanotechnology," Proceedings of the Combustion Institute, vol. 32, no. 2, pp. 1819-1838, 2008.

[9] G. A. Risha, B. J. Evans, E. Boyer, R. B. Wehrmann, and K. K. Kuo, "Nano-sized aluminum- and boron-based solid-fuel characterization in a hybrid rockey engine," in Proceedings of the 39th AIAA/ASME/SAE/ASEE Joint Propulsion Conference, July 2003.

[10] L. D. Smoot and C. F. Price, "Regression rates of nonmetallized hybrid fuels systems," AIAA Journal, vol. 3, pp. 1408-1413, 1965.

[11] L. D. Strand, M. D. Jones, R. L. Ray, and N. S. Cohen, "Characterization of hybrid rocket internal heat flux and HTPB fuel pyrolysis," in Proceedings of the 30th AIAA/ASME/SAE/ASEE Joint Propulsion Conference, June 1994.

[12] P. Estey, D. Altman, and J. McFarlane, "An evaluation of scaling effects for hybrid rocket motors," in Proceedings of the 27th AIAA/ASME/SAE/ASEE Joint Propulsion Conference, June 1991.

[13] M. J. Chiaverini, K. K. Kuo, A. Peretz, and G. C. Harting, "Regression-rate and heat-transfer correlations for hybrid rocket combustion," Journal of Propulsion and Power, vol. 17, no. 1, pp. 99-110, 2001.

[14] A. Gany, "Comprehensive consideration of boron combustion in airbreathing propulsion," in Proceedings of the 42nd AIAA/ASME/SAE/ASEE Joint Propulsion Conference, pp. 25922603, July 2006.

[15] L. T. DeLuca, L. Galfetti, G. Colombo et al., "Innovative solid fuels and propellants loaded with metals and hydrides," SPLab Report to CNES under Commande No. 4700028003/DLA094, 2009.

[16] L. T. DeLuca, L. Galfetti, G. Colombo et al., "Time-resolved burning of solid fuels for hybrid rocket propulsion," in Advances in Propulsion Physics, vol. 2, pp. 341-362, Taurus Press, Moscow, Russia, 2011.

[17] T. J. Houser and M. V. Peck, "Research in hybrid combustion," in AIAA Progress in Astronautics and Aeronautics, Heterogeneous Combustion, H. G. Wolfhard, I. Glassman, and L. Green Jr., Eds., pp. 559-581, 1964.

[18] B. Evans, N. A. Favorito, E. Boyer, G. A. Risha, R. B. Wehrman, and K. K. Kuo, "Characterization of nanosized energetic particle enhancement of solid-fuel burning rates in an X-ray transparent hybrid rocket engine," in Proceedings of the AIAA/ASME/SAE/ASEE Joint Propulsion Conference and Exhibit, Fort Lauderdale, Fla, USA, July 2004.

[19] T. J. Ohlemiller and M. Summerfield, "A critical analysis of arc image ignition of solid propellants," AIAA Journal, vol. 6, no. 5, pp. 878-886, 1967.

[20] F. P. Incropera and D. de Witt, Fundamentals of Heat and Mass Transfer, John Wiley \& Sons, 3rd edition, 1990.

[21] Y. S. Kwon, A. A. Gromov, A. P. Ilyin, and G. H. Rim, "Passivation process for superfine aluminum powders obtained by electrical explosion of wires," Applied Surface Science, vol. 211, no. 1-4, pp. 57-67, 2003.

[22] Y. F. Ivanov, M. N. Osmonoliev, V. S. Sedoi et al., "Productions of ultra-fine powders and their use in high energetic compositions," Propellants, Explosives, Pyrotechnics, vol. 28, no. 6, pp. 319-333, 2003.

[23] A. A. Gromov, A. P. Il'In, U. Foerter-Barth, and U. Teipel, "Effect of the passivating coating type, particle size, and storage time on oxidation and nitridation of aluminum powders," Combustion, Explosion and Shock Waves, vol. 42, no. 2, pp. 177-184, 2006. 
[24] P. Selvam, B. Viswanathan, C. S. Swamy, and V. Srinivasan, "Magnesium and magnesium alloy hydrides," International Journal of Hydrogen Energy, vol. 11, no. 3, pp. 169-192, 1986.

[25] G. Lengellé, J. C. Gordon, B. Fourest, and C. Guin, "Condensed-phase behavior and ablation rate of fuels for hybrid propulsion," in Proceedings of the 9th Joint Propulsion Conference and Exhibit, June 1993.

[26] M. A. Karabeyoglu, D. Altman, and B. J. Cantwell, "Combustion of liquefying hybrid propellants: part 1, General theory," Journal of Propulsion and Power, vol. 18, no. 3, pp. 610-620, 2002.

[27] D. A. Kearney and W. W. Geiman, "Accounting for planned fuel expulsion by hybrid rockets," in Proceedings of the 41st AIAA/ASME/SAE/ASEE Joint Propulsion Conference and Exhibit, Tucson, Ariz, USA, July 2005.

[28] B. Evans, N. A. Favorito, E. Boyer, and K. K. Kuo, "Characterization of solid fuel mass-burning enhancement utilizing an x-ray translucent hybrid rocket motor," in Proceedings of the 7th International Symposium on Special Topics in Chemical Propulsion, pp. 705-724, 2005.

[29] B. Evans, N. A. Favorito, and K. K. Kuo, "Oxidizer-type and aluminum-particle addition effects on solid-fuel burning behavior," in Proceedings of the 42nd AIAA/ASME/SAE/ASEE Joint Propulsion Conference, pp. 3538-3547, Sacramento, Calif, USA, July 2006.

[30] D. R. Greatrix, "Model for predicting fuel regression rate in hybrid rocket engines," in Proceedings of the 43rd AIAA/ASME/SAE/ASEE Joint Propulsion Conference, pp. 34363443, July 2007.

[31] G. A. Risha, G. C. Harting, K. K. Kuo et al., "Pyrolysis and combustion of solid fuels in various oxidizing environments," in Proceedings of the 34th AIAA/ASME/SAE/ASEE Joint Propulsion Conference, pp. 98-3184, Cleveland, Ohio, USA, July 1998.

[32] M. J. Chiaverini, N. Serin, D. K. Johnson, Y. C. Lu, K. K. Kuo, and G. A. Risha, "Regression rate behavior of hybrid rocket solid fuels," Journal of Propulsion and Power, vol. 16, no. 1, pp. 125-132, 2000.

[33] M. F. Modest, Radiative Heat Transfer, McGraw-Hill, New York, NY, USA, 1993.

[34] M. Q. Brewster and D. M. Taylor, "Radiative properties of burning aluminum droplets," Combustion and Flame, vol. 72, no. 3, pp. 287-299, 1988. 

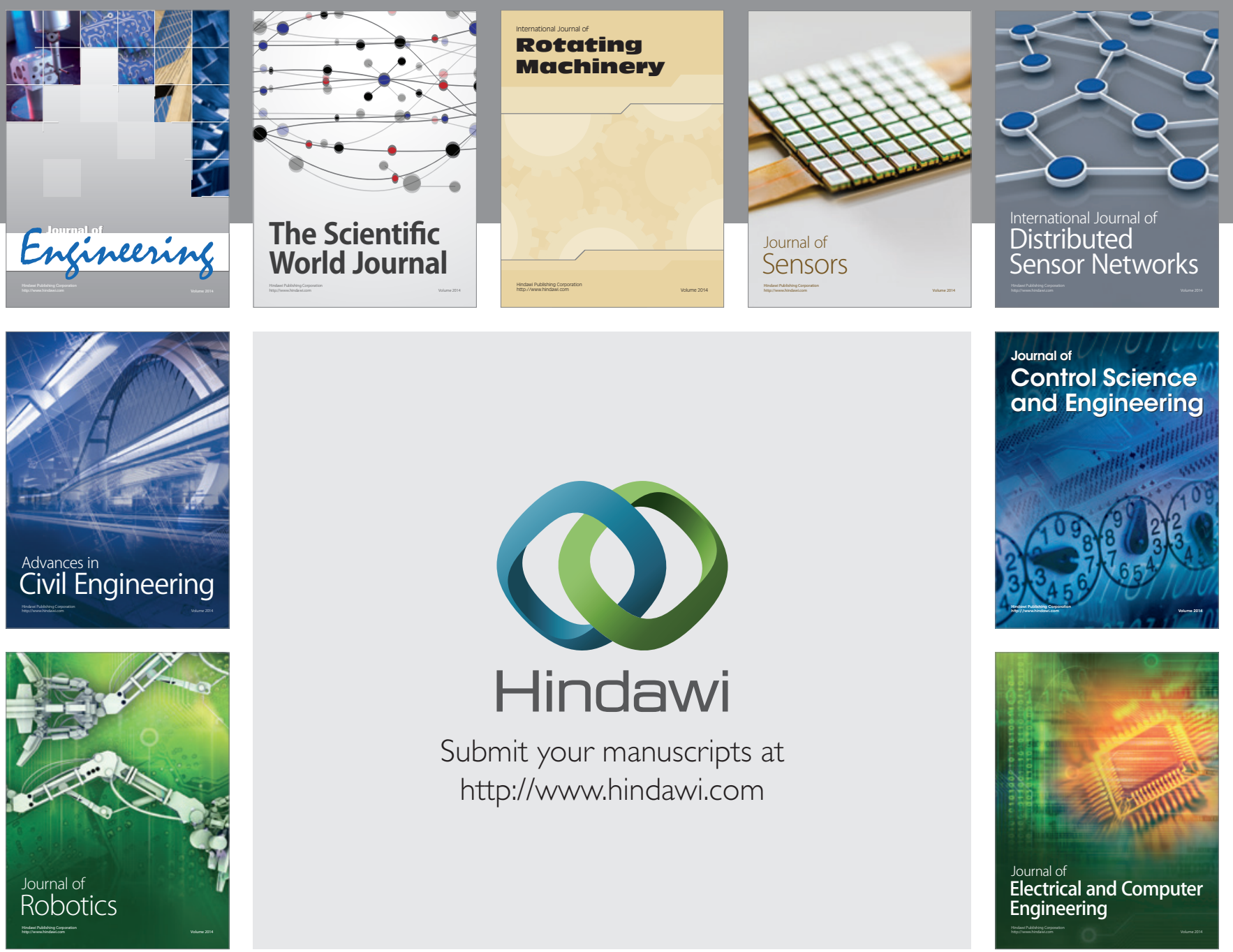

Submit your manuscripts at

http://www.hindawi.com
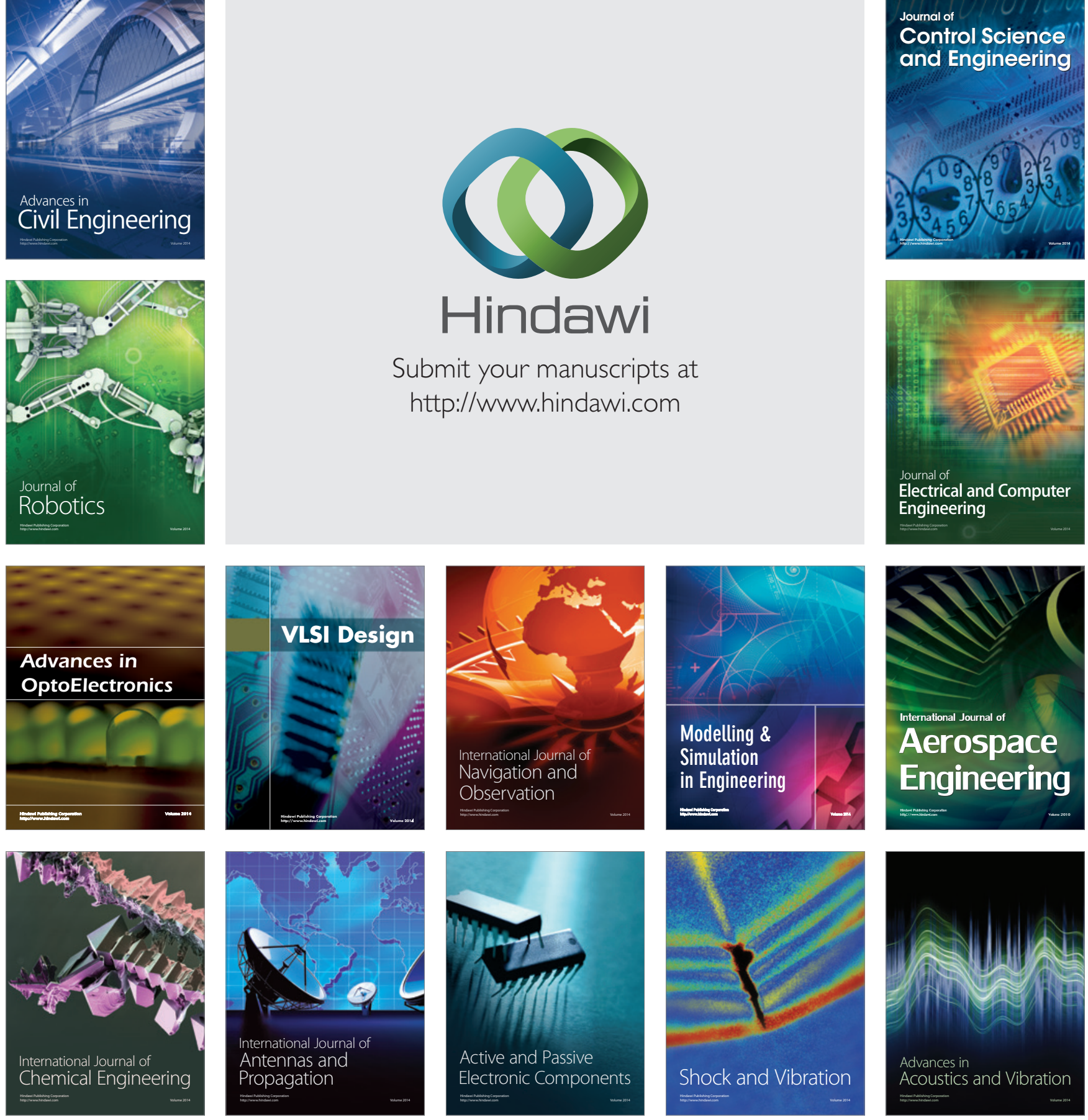